Article

\title{
Frequency-Dependent Multi-Well Cardiotoxicity Screening Enabled by Optogenetic Stimulation
}

\author{
Susanne Rehnelt ${ }^{1}$, Daniela Malan ${ }^{1}$, Krisztina Juhasz ${ }^{2,3}$, Benjamin Wolters ${ }^{4}$, Leo Doerr ${ }^{2}$, \\ Matthias Beckler ${ }^{2}$, Ralf Kettenhofen ${ }^{4}$, Heribert Bohlen ${ }^{4}$, Tobias Bruegmann 1,5,* \\ and Philipp Sasse ${ }^{1, *}$ \\ 1 Institute of Physiology I, Medical Faculty, University of Bonn, 53127 Bonn, Germany; \\ s4surehn@uni-bonn.de (S.R.); dmalan@uni-bonn.de (D.M.) \\ 2 Nanion Technologies GmbH, 80636 Munich, Germany; krisztina.juhasz@nanion.de (K.J.); \\ leo.doerr@nanion.de (L.D.); matthias.beckler@nanion.de (M.B.) \\ 3 Present address: Institute for Nanoelectronics, Department of Electrical Engineering and Information \\ Technology, Technische Universität München, 80339 Munich, Germany \\ 4 Part of the Ncardia Group, Axiogenesis AG, 50829 Cologne, Germany; \\ benjamin.wolters@ncardia.com (B.W.); ralf.kettenhofen@ncardia.com (R.K.); \\ heribert.bohlen@ncardia.com (H.B.) \\ 5 Research Training Group 1873, University of Bonn, 53127 Bonn, Germany \\ * Correspondence: tbruegmann@uni-bonn.de (T.B.); philipp.sasse@uni-bonn.de (P.S.); \\ Tel.: +49-(0)228-6885-200 (T.B. \& P.S.)
}

Received: 30 October 2017; Accepted: 30 November 2017; Published: 6 December 2017

\begin{abstract}
Side effects on cardiac ion channels causing lethal arrhythmias are one major reason for drug withdrawals from the market. Field potential (FP) recording from cardiomyocytes, is a well-suited tool to assess such cardiotoxic effects of drug candidates in preclinical drug development, but it is currently limited to the spontaneous beating of the cardiomyocytes and manual analysis. Herein, we present a novel optogenetic cardiotoxicity screening system suited for the parallel automated frequency-dependent analysis of drug effects on FP recorded from human pluripotent stem cell-derived cardiomyocytes. For the expression of the light-sensitive cation channel Channelrhodopsin-2, we optimised protocols using virus transduction or transient mRNA transfection. Optical stimulation was performed with a new light-emitting diode lid for a 96-well FP recording system. This enabled reliable pacing at physiologically relevant heart rates and robust recording of FP. Thereby we detected rate-dependent effects of drugs on $\mathrm{Na}^{+}, \mathrm{Ca}^{2+}$ and $\mathrm{K}^{+}$ channel function indicated by FP prolongation, FP shortening and the slowing of the FP downstroke component, as well as generation of afterdepolarisations. Taken together, we present a scalable approach for preclinical frequency-dependent screening of drug effects on cardiac electrophysiology. Importantly, we show that the recording and analysis can be fully automated and the technology is readily available using commercial products.
\end{abstract}

Keywords: optogenetics; field potential; long QT syndrome; cardiotoxicity screening; heart rate; cardiomyocytes; induced pluripotent stem cells

\section{Introduction}

Since 1953, over 60 drugs have had to be withdrawn from the market because of the risk of cardiac arrhythmia [1] leading to sudden cardiac death [2]. Therefore, better methods are required to enhance the quality and power of preclinical safety screenings [3] to ensure patients' safety and to save billions of dollars because of late-stage drug withdrawals [4-6]. One of the most common cardiotoxic effects is delayed cardiac repolarisation, which clinically manifests in the electrocardiogram (ECG) as 
a prolonged QT interval and which is strongly associated with lethal ventricular tachyarrhythmias of the Torsades de Pointes type [2]. Therefore, the International Conference on Harmonization's guideline S7B established rules for assessing the cardiac safety of newly developed drugs before entering into clinical trials [7]. This guideline focuses on in vitro experiments measuring the rapid potassium current $\left(\mathrm{I}_{\mathrm{Kr}}\right)$ through the human Ether-a-go-go Related Gene (hERG) channel expressed in heterologous cell lines, which was considered to be the best surrogate measurements for delayed repolarisation [7], because the inhibition of hERG channels is responsible for most instances of drug-induced Long QT syndrome $[5,8,9]$. However, screening systems relying on measuring one type of ion channels do not take into account side effects on other cardiac ion channels, which can also be highly proarrhythmic. For instance, inhibiting $\mathrm{Ca}^{2+}$ channels lead to faster repolarisation and short QT syndromes, and blocking $\mathrm{Na}^{+}$channels results in slowed and dispersed electrical conduction and Brugada syndromes, which can both be highly proarrhythmic $[2,5,8,10]$. Furthermore, it is possible that drugs affecting multiple ion channels cause several effects which neutralise each other and such drugs would be unnecessarily rejected when relying on a single channel assay [11]. Thus, in contrast to heterologous expression systems, intact human cardiomyocytes with all channels present in their native environment would be the best suited screening system for analysing cardiotoxic side effect of drugs. To take these considerations into account, the "comprehensive in vitro proarrhythmia assay" (CiPA) initiative was launched in 2013 with the aim to validate novel cardiotoxicity screening systems towards a multimodal assessment of various cardiac ion channels. One of the CiPA demands was to analyse drug effects on human cardiomyocytes [9]. For this purpose, human pluripotent stem cell (hPSC)-derived cardiomyocytes provide a cost-efficient and reproducible source with high similarity in ion channel composition to adult human cardiomyocytes [12,13].

The manual patch clamp is the gold standard technique to investigate the electrophysiology of cardiomyocytes, but is also very time consuming and the duration of experiments is limited due to rundown of cytosolic stability [14]. Analysis of the electrical activity by recording extracellular field potentials (FP) with microelectrode arrays (MEA) is a non-invasive and well-suited alternative enabling high throughput assays [15]. FP signals reflect the action potential (AP) shape, making it possible to extract relevant AP parameters: The initial rapid component of the FP correlates to the AP upstroke velocity and quantification by measuring the maximum negative downstroke velocity (max.DV) is a well-suited surrogate parameter for $\mathrm{Na}^{+}$channel activity [16,17]. In addition, the FP consists of a deflection at the end similar to the T-wave in the human ECG. This allows the straightforward determination of field potential duration (FPD), which is highly correlated to the AP duration (APD) [16]. Thus, parameters analysed from FP recordings make it possible to assess the cardiac safety of drugs. Therefore, recording FP with MEA has gained more and more importance in the last decade $[5,6,16,18-26]$. This is also due to its easy-to-use commercially available instrumentation, as well as the very high temporal resolution, which is in contrast to voltage imaging technologies that require dye-loading, high-intensity illumination and custom-built recording devices [27-29]. However, the FP recording technology still faces limitations towards industrial cardiotoxicity screening in pharmaceutical companies. Automated analysis is often not possible because FP recorded from small individual electrodes show severe variations in FP shape, requiring manual selection and biased analysis by investigators [6,15]. Using larger electrodes $(>500 \mu \mathrm{m})$ that record one FP from thousands of cardiomyocytes simultaneously leads to robust FP signals with lower variation between electrodes. However, the non-synchronous electrical activity due to the conduction through the electrical syncytium on a large electrode results in fragmented signals during the initial rapid fast component of the FP, which prevents proper analysis of the $\mathrm{Na}^{+}$channel availability [30]. The second important limitation is that FP recordings are restricted to the spontaneous activity of cardiomyocytes because electrical stimulation is technically very challenging and induces large stimulation artefacts [31-33]. However, the effects of drugs on cardiac ion channels can be strongly dependent on the beating rate due to intrinsic biophysical properties of the proteins and the use-dependency of drugs [34,35]. Importantly, better differentiation and selection protocols to 
obtain more mature hPSC-derived cardiomyocytes are emerging [36-38], which will ultimately result in electrical silent ventricular-like cardiomyocytes with stable resting potential, which will make pacing indispensable.

To overcome these limitations, we recently combined optogenetic stimulation and FP recordings on MEA. We used brief blue light $(470 \mathrm{~nm})$ pulses to reliably pace Channelrhodopsin-2 (ChR2) expressing hPSC-derived cardiomyocytes at physiological heart rates from 1 to $2.5 \mathrm{~Hz}$ (60 to $150 \mathrm{bpm}$ ). In addition, global illumination of cardiomyocytes on all 60 recording electrodes of one multi-electrode MEA induced simultaneous electrical activity without any detectable conduction delay. This allowed spatial averaging of FP from all electrodes resulting in a robust FP shape similar to using one large electrode [30], but without fragmentation of the initial fast rapid component. Using this technology, we were able to analyse FPD and max.DV and thereby detected frequency-dependent drug effects on $\mathrm{Na}^{+}, \mathrm{Ca}^{2+}$ and $\mathrm{K}^{+}$channels [17]. However, these experiments were performed in a low throughput format using a single-well MEA system and a custom designed lens-based optogenetic stimulation that does not allow upscaling, as required for industrial drug screening.

Therefore, in this report, we combined optogenetic pacing of hPSC-derived cardiomyocytes with a commercially available 96-well screening platform (CardioExcyte96, Nanion Technologies, Munich, Germany) equipped with one large FP recording electrode per well [30] to enable fully automated frequency-dependent cardiotoxicity screening. For this purpose, we optimised ChR2 mRNA- or virus-based gene transfer and developed light-emitting diode (LED) lids for exact optogenetic stimulation of hPSC-derived cardiomyocytes at physiological heart rates from 1 to 3 $\mathrm{Hz}$ (60 to $180 \mathrm{bpm}$ ). Using specific ion channel blockers, we confirmed the cardiac ion channels involved in the different parts of the FP and applying known arrhythmogenic drugs, we proved the concept for cardiotoxicity screening. Importantly, we demonstrate that this technology can be performed with commercially available products and can be fully automated.

\section{Results}

\subsection{Establishing LED-Based Optogenetic Pacing on 96-Wells Plates}

The CardioExcyte96 system is an extracellular FP and impedance amplifier using a 96-well plate with one gold recording electrode of $2 \mathrm{~mm}$ diameter in the centre of each well and one reference electrode at the side [30]. To globally illuminate every single well of the 96-well CardioExcyte sensor plate, we custom built an LED lid containing 96 high-power $470 \mathrm{~nm}$ LEDs (NSPB500AS, Nichia, Tokushima, Japan) with a radiation angle of $\sim 20^{\circ}$ to ensure illumination of the whole recording electrode in each well (Figure 1A,B). LEDs were driven with short constant current pulses $(100 \mathrm{~mA})$, resulting in a light intensity of $1.4 \mathrm{~mW} / \mathrm{mm}^{2}$ at the cell level. Maximum light intensity was reached in less than $40 \mu$ s (Figure 1C), allowing efficient stimulation with precise light pulses in the millisecond range.

A

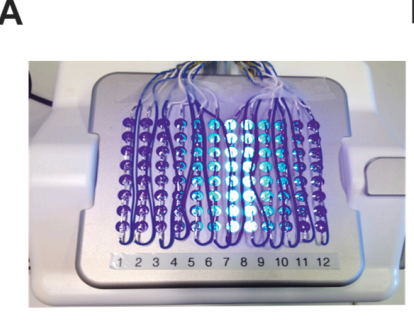

B

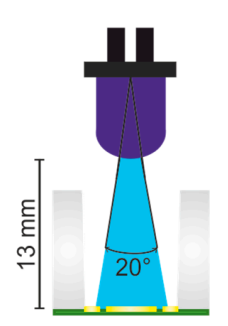

C

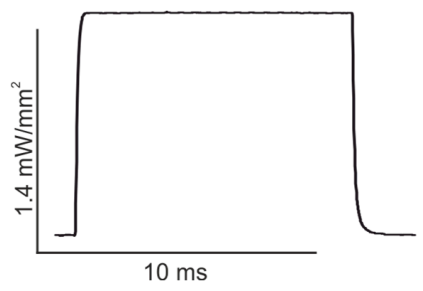

Figure 1. Custom-built prototype of a LED lid for the CardioExcyte96 system. (A) Picture of the lid containing 96 blue LEDs; (B) sketch of a single well with one LED placed $13 \mathrm{~mm}$ above the recording electrode (yellow) with an illumination angle of $20^{\circ}$; (C) light intensity of a $10 \mathrm{~ms}$ long light pulse at the level of the recording electrode. 


\subsection{Maturation and Optical Pacing of Cardiomyocytes}

Commercially available hPSC-derived cardiomyocytes (Cor. $4 \mathrm{U}^{\circledR}, \mathrm{Ncardia}$, Cologne, Germany) were transduced with an adeno-associated virus (AAV) to express the light-gated non-selective cation channel ChR2 [39] in fusion to the red fluorescent protein mCherry. One day after infection, cells were plated on the recording electrodes of the CardioExcyte sensor plates where they formed a spontaneously beating confluent monolayer. The FP were recorded over four weeks and we observed electrophysiological "maturation" of the FP signals over time similar to a recent report using human cardiomyocytes differentiated from embryonic stem cells [40]. This became evident by a $50 \%$ slowing of the spontaneous beating rate from week 1 to week 4 (Figure 2A). In addition, we characterised the FP shape using $1 \mathrm{~Hz}$ optical stimulation (stimulation parameters see below) and found that the max.DV increased by $256 \%$ over time (Figure 2B,C). This is in line with a recent report and indicates higher $\mathrm{Na}^{+}$ channel expression [40]. Furthermore, we found a shortening of the FPD over time from week 1 to week 4 by $28 \%$, and a more pronounced repolarisation wave (Figure $2 \mathrm{~B}, \mathrm{D}$ ) which could be explained by a higher level of repolarisation $\mathrm{K}^{+}$currents or better electrical synchronisation of cardiomyocytes.

Thus, in this study, we measured FP signals three to four weeks after ChR2 gene transfer and cardiomyocyte plating on the CardioExcyte sensor plates. To prove that the single AAV-based gene transfer was still sufficient, we assessed ChR2 expression and function three weeks after infection. Cardiomyocytes showed membrane bound ChR2 expression (Figure 2E) and fluorescence-activated cell sorting (FACS)-analysis revealed that $70 \pm 11 \%(n=3)$ of cells were positive for ChR2 (Figure 2F).

A
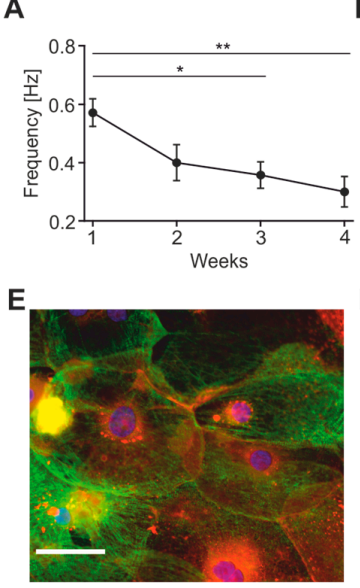

B
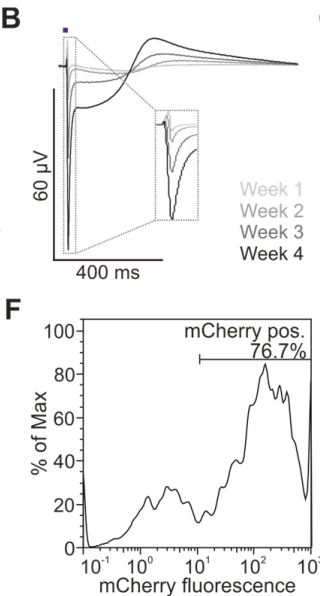

C

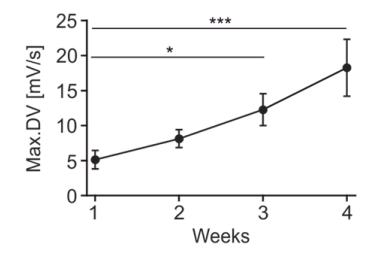

D

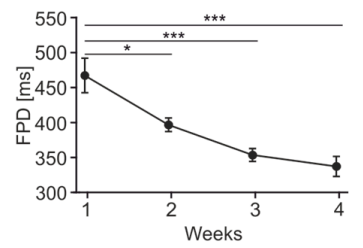

Figure 2. Analysis of field potential (FP) signals over four weeks after adeno-associated virus (AAV)-transduction and plating of human pluripotent stem cell (hPSC)-derived cardiomyocytes. (A) Spontaneous beat rate over time (from week 1 to week $4:-47 \pm 17 \% ; p=0.0077 ; n=7) ;($ B) overlay of representative FP optically paced at $1 \mathrm{~Hz}$ (blue bar); (C) analysis of maximum negative downstroke velocity (max.DV) (from week 1 to week $4:+256 \pm 22 \% ; p=0.0005 ; n=7$ ) and (D) field potential duration (FPD) over time (from week 1 to week 4 : $-28 \pm 4 \% ; p<0.0001 ; n=7$ ); (E) microscope picture of Channelrhodopsin-2 (ChR2)-expressing Cor.4 $\mathrm{U}^{\circledR}$ cells taken at week 3 (blue $=$ DAPI, green $=$ Troponin $\mathrm{T}$, red $=$ mCherry from ChR2-mCherry fusion protein, scale bar: $50 \mu \mathrm{m}) ;(\mathrm{F})$ representative $(n$ $=3$ ) fluorescence-activated cell sorting (FACS)-profile of ChR2-mCherry positive cells at week $3 .{ }^{*} p<$ $0.05,{ }^{* *} p<0.01,{ }^{* * *} p<0.001$.

\subsection{Frequency Dependence of FP Parameters}

We next tested the minimal requirement of light stimulation with the custom-built LED lid and found that light pulses $\left(1.4 \mathrm{~mW} / \mathrm{mm}^{2}\right)$ as short as $2 \mathrm{~ms}$ were sufficient for reliable pacing at frequencies between 1 and $3 \mathrm{~Hz}$ (Figure 3A). In accordance to our previous study [17], we could detect frequency-dependent changes of the FP parameters. The max.DV decreased from 1 to $3 \mathrm{~Hz}$ by $47 \%$ (Figure 3B,C) and the FPD shortened from 1 to $3 \mathrm{~Hz}$ by $43 \%$ (Figure 3B,D). The latter finding is in full 
accordance with the physiological APD shortening measured in human cardiomyocytes [41] and QT shortening seen in the human ECG [42] at higher heart rates.

Adrenergic stimulation results in faster and stronger beating of the heart and shortening of AP through the $\mathrm{G}_{\mathrm{s}}$-signalling pathway and phosphorylation of $\mathrm{Ca}^{2+}$ channels, ryanodine receptors and repolarising $\mathrm{K}^{+}$channels. To detect this physiological effect with our approach, we applied the $\beta$-adrenergic agonist Isoprenaline $(300 \mathrm{nM}$, Figure $3 \mathrm{E}$, left). This increased the spontaneous beating rate from $0.25 \pm 0.003$ to $0.96 \pm 0.11 \mathrm{~Hz}(p<0.0001, n=29)$ proving the positive chronotropic effect $[5,43]$. While Isoprenaline had no effect on the max.DV (Figure 3E, middle), it significantly reduced the FPD at all frequencies except at $3 \mathrm{~Hz}$ (Figure 3E, right), suggesting an augmentation of repolarising $\mathrm{K}^{+}$currents.

A

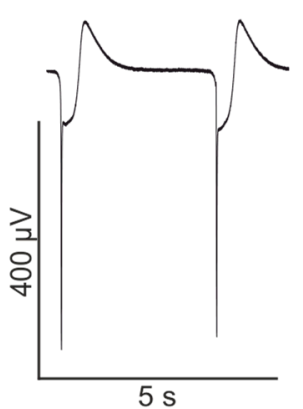

B

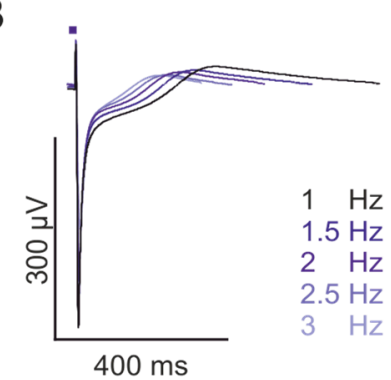

$\mathbf{E}$

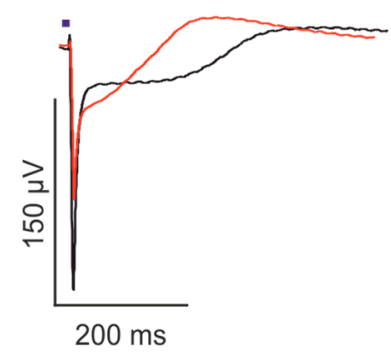

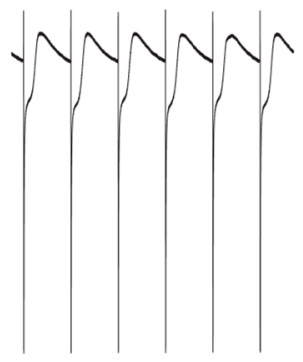
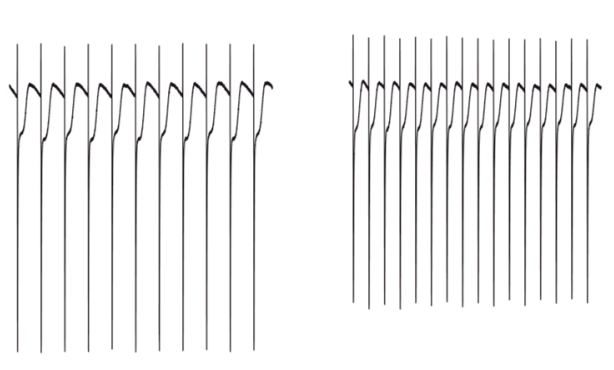

C
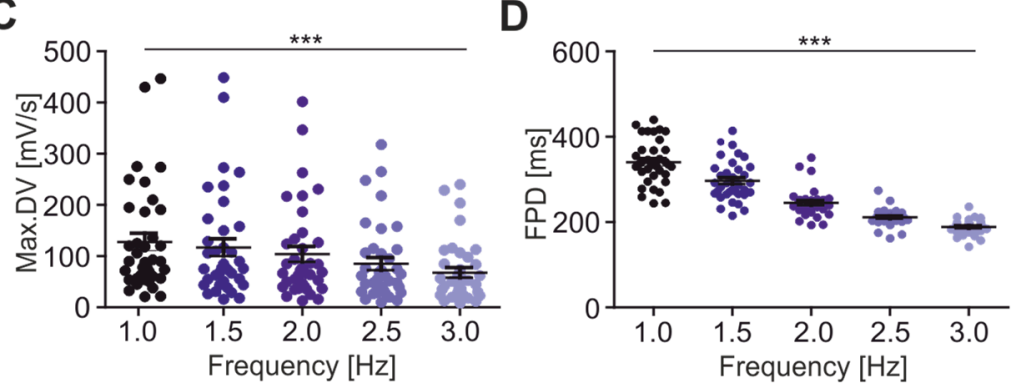

Control / Isoprenaline (300 nM)

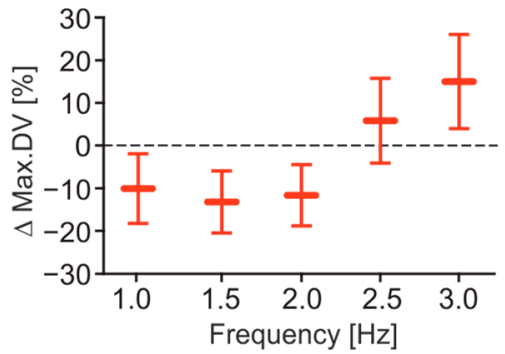

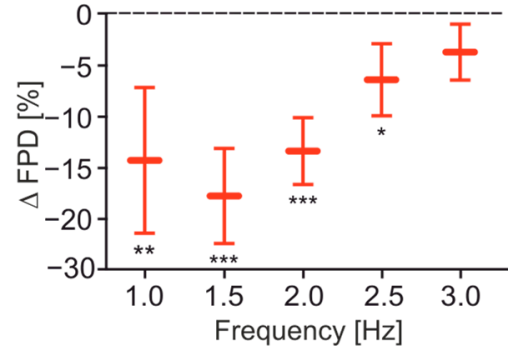

Figure 3. Optogenetically paced FP at various physiological stimulation rates. (A) Representative FP traces during (from left to right) spontaneous beating and optical pacing (blue bars) at $1 \mathrm{~Hz}, 2 \mathrm{~Hz}$ and $3 \mathrm{~Hz}$; (B) overlay of representative FP paced at frequencies 1-3 Hz (from black to light blue); (C) statistical analysis of absolute values of max.DV (from 1 to $3 \mathrm{~Hz}$ : $-47 \pm 14 \%, p<0.0001, n=37$ ) and (D) FPD (from 1 to $3 \mathrm{~Hz}:-43 \pm 1 \%, p<0.0001, n=42$ ); (E) Representative FP before and after application of $300 \mathrm{nM}$ Isoprenaline and relative changes of max.DV (middle) and FPD (right) $(n=24)$. ${ }^{*} p<0.05,{ }^{* *} p<0.01,{ }^{* * *} p<0.001$.

\subsection{Pharmacological Characterisation of FP Signals}

To prove that optogenetically paced FP signals allow the detection of specific effects on the three major cardiac ion channels, we tested $\mathrm{Na}^{+}, \mathrm{Ca}^{2+}$ and $\mathrm{K}^{+}$current blockers at various physiological heart 
rates. Specifically, we applied the $\mathrm{Na}^{+}$channel blocker Lidocaine $(300 \mu \mathrm{M})$ and found a significant reduction of the max.DV parameter at all frequencies but, importantly, no unspecific side effects on the FPD (Figure 4A). Nifedipine, a highly specific $\mathrm{Ca}^{2+}$ channel blocker, reduced the max.DV at all pacing rates and additionally shortened the plateau phase of the FP and thereby reduced the FPD in a dose-dependent manner (Figure 4B). This data indicates that the max.DV parameter is not only influenced by $\mathrm{Na}^{+}$, but also by $\mathrm{Ca}^{2+}$ channel function. The latter can be explained by the rather immature status of the hPSC-derived cardiomyocytes with elevated resting membrane potentials [44].

Interestingly, the effect of Nifedipine on FPD shortening was strongest at low heart rates and high concentrations (100 nM, Figure 4B right) nearly abolished the rate-dependency of FPD. This suggests that refractoriness of $\mathrm{Ca}^{2+}$ channels is one important mechanism for the shortening of FPD at higher heart rates in hPSC-derived cardiomyocytes, which was described before $[17,41]$. To determine the effect of repolarising $\mathrm{K}^{+}$currents, we applied E4031, which is a specific blocker for hERG $\mathrm{K}^{+}$channels at low concentrations. While already using a very low dose of $10 \mathrm{nM}$ E4031, we detected a delayed repolarisation phase with prolonged FPD, which is in line with recent reports $[22,24,25,45]$. However this effect was most prominent at slow beating rates and not present at $3 \mathrm{~Hz}$ pacing (Figure 4C). Furthermore, E4031 showed an unexpected side effect of reduced max.DV at high beating rates (Figure 4C), which could be explained by elevation of resting membrane potentials and subsequent inactivating of depolarising $\mathrm{Na}^{+}$currents or by prolonged APs and refractoriness, leading to shorter repolarisation phase for $\mathrm{Na}^{+}$recovery from inactivation.

Taken together, these results demonstrate that the robust shape of the optogenetically paced FP allows the detection of drug effects on three main cardiac ion channels, which could be quantified automatically due to the characteristic changes within the FP.
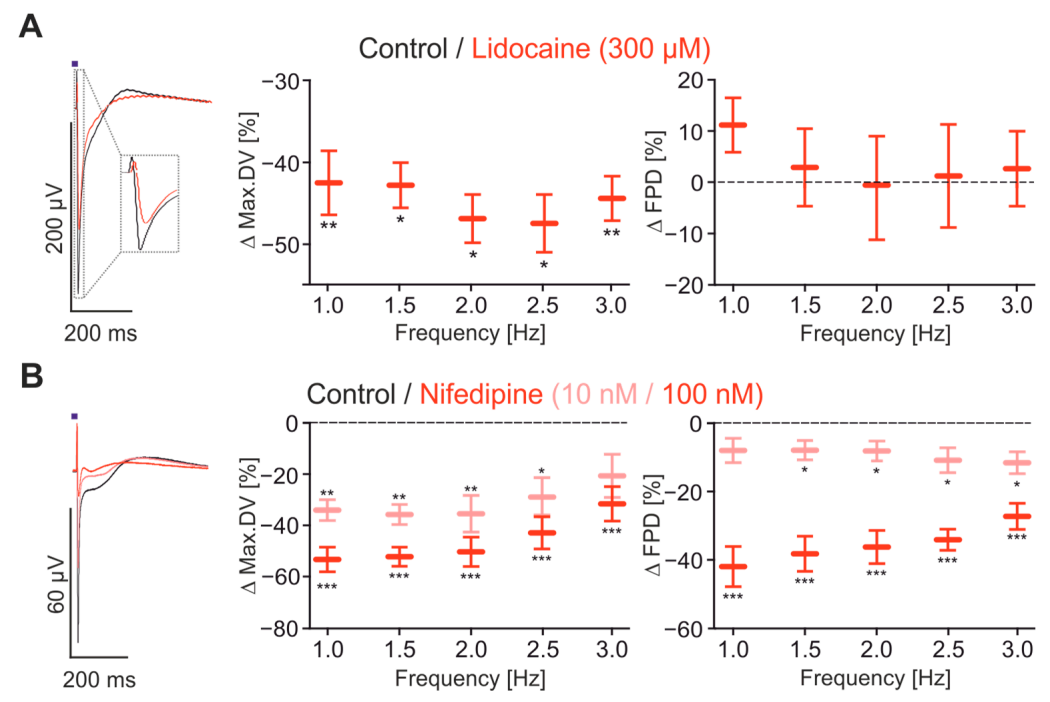

C
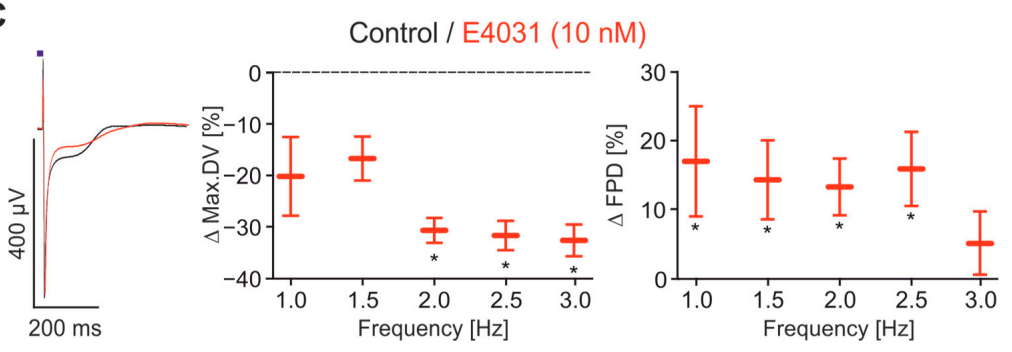

Figure 4. Pharmacological characterisation of FP parameters. (A-C) Overlay of representative FP optically paced at $1 \mathrm{~Hz}$ (left) before (black) and after drug application (red), and statistical analysis of the relative changes of max.DV (middle) and FPD (right) at the frequencies 1-3 Hz; (A) effects of $300 \mu \mathrm{M}$ Lidocaine $(n=7-8) ;(\mathbf{B})$ effects of $10 \mathrm{nM}(n=7)$ and $100 \mathrm{nM}(n=11)$ Nifedipine; (C) effects of $10 \mathrm{nM} \operatorname{E4031}(n=12-17) .{ }^{*} p<0.05,{ }^{* *} p<0.01,{ }^{* * *} p<0.001$. 


\subsection{Evaluation of Drug Screening with the CardioExcyte96 System}

To assess if our approach is suitable for cardiotoxic drug screening, we next tested the effect of known arrhythmogenic substances. First, we investigated the $\beta$-blocker Sotalol, which is known to block also hERG $\mathrm{K}^{+}$channels and thereby induce a pharmacological Long QT syndrome with the high risk of arrhythmia [33,46]. The application of $10 \mu \mathrm{M}$ of Sotalol significantly prolonged the FPD but only at the low frequencies of 1 and $1.5 \mathrm{~Hz}$, and not at higher frequencies (Figure 5A). In addition, Sotalol significantly reduced the max.DV with strongest effects at frequencies $>2 \mathrm{~Hz}$ (Figure $5 \mathrm{~A}$ middle).

To test if our system detects side effects on $\mathrm{Na}^{+}$channels that could lead to drug-induced Brugada syndrome [5,47], we applied the class Ic anti-arrhythmic drug Flecainide, a blocker for the fast $\mathrm{Na}^{+}$ current, which significantly reduced the max.DV parameter in a dose-dependent manner (Figure 5B). Interestingly, high concentrations of Flecainide $(3 \mu \mathrm{M})$ also affected the FPD in a frequency-dependent manner. At low pacing rates $(1 \mathrm{~Hz})$, the FPD was significantly prolonged, whereas at high rates $(>2 \mathrm{~Hz})$ the FPD was clearly reduced (Figure $5 \mathrm{~B}$ right).

A

Control / Sotalol $(10 \mu \mathrm{M})$
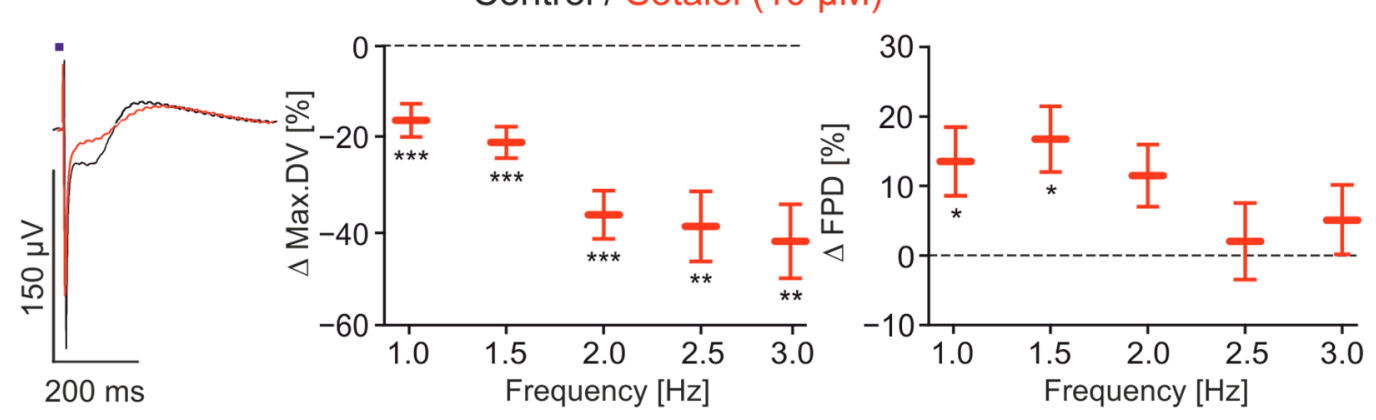

B

Control / Flecainide $(0.3 \mu \mathrm{M} / 1 \mu \mathrm{M} / 3 \mu \mathrm{M})$
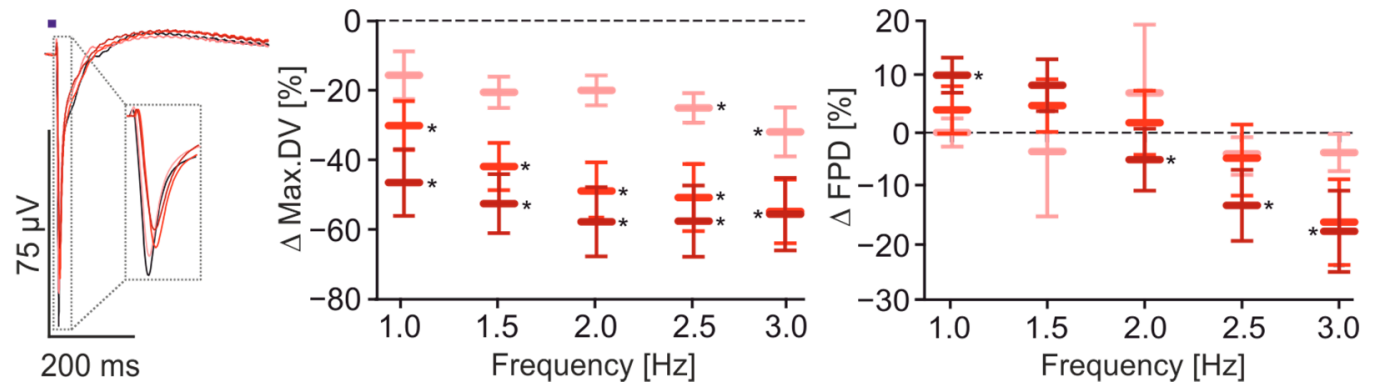

Figure 5. Analysis of drug effects on FP. (A,B) Overlay of representative FP optical paced at $1 \mathrm{~Hz}$ (left) before (black) and after drug application (red), and statistical analysis of the relative changes of max.DV (middle) and FPD (right) at the frequencies 1-3 Hz. (A) Effects of $10 \mu \mathrm{M}$ Sotalol ( $n=13-17)$; (B) effects of $0.3,1$ and $3 \mu \mathrm{M}$ Flecainide $(n=11-12){ }^{*} p<0.05,{ }^{* *} p<0.01,{ }^{* * *} p<0.001$.

It is known that cardiac glycosides can cause arrhythmias [48-50], through the indirect blocking of the $\mathrm{Na}^{+} / \mathrm{Ca}^{2+}$ exchanger and $\mathrm{Ca}^{2+}$ accumulation. To test for such effects, we applied Digoxin at two concentrations ( 1 and $10 \mu \mathrm{M})$, which consistently reduced the max.DV in a dose-dependent manner and shortened the FPD at almost all beating rates (Figure 6A). In particular, the latter effect is in accordance with recent studies [51], and reports demonstrating that Digoxin can shorten the QT duration in the ECG $[49,50]$ and that this could be due to $\mathrm{Ca}^{2+}$-dependent inactivation of L-Type $\mathrm{Ca}^{2+}$-channels [52]. Importantly, in the presence of $10 \mu \mathrm{M}$ Digoxin, we observed afterdepolarisations occurring at the end of the repolarisation phase of the FP (Figure 6B). Interestingly the afterdepolarisations occurred only at low pacing rates $(<1.5 \mathrm{~Hz})$ and were not seen at higher rates (Figure 6C). We speculate that these signals result from spontaneous $\mathrm{Ca}^{2+}$ release events which 
are thought to be responsible for arrhythmias induced by intoxication of cardiac glycosides [48]. Importantly, the rate dependency of the proarrhythmic effect of Digoxin has also been observed in $\mathrm{AP}$ and ECG recordings [53]. Interestingly, in the presence of $10 \mu \mathrm{M}$ Digoxin one FP recording from spontaneously beating cardiomyocytes showed a transition from a state characterized by regular afterdepolarisations to a state without afterdepolarisations, but with twice the beating rate, suggesting that in the latter state each afterdepolarisation triggers an AP (Figure 6D).

A Control / Digoxin $(1 \mu \mathrm{M} / 10 \mu \mathrm{M})$
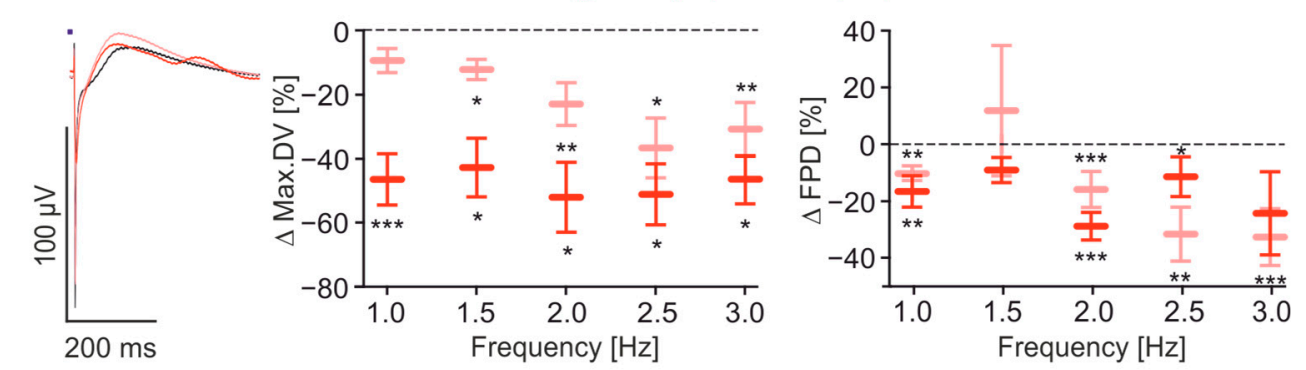

B
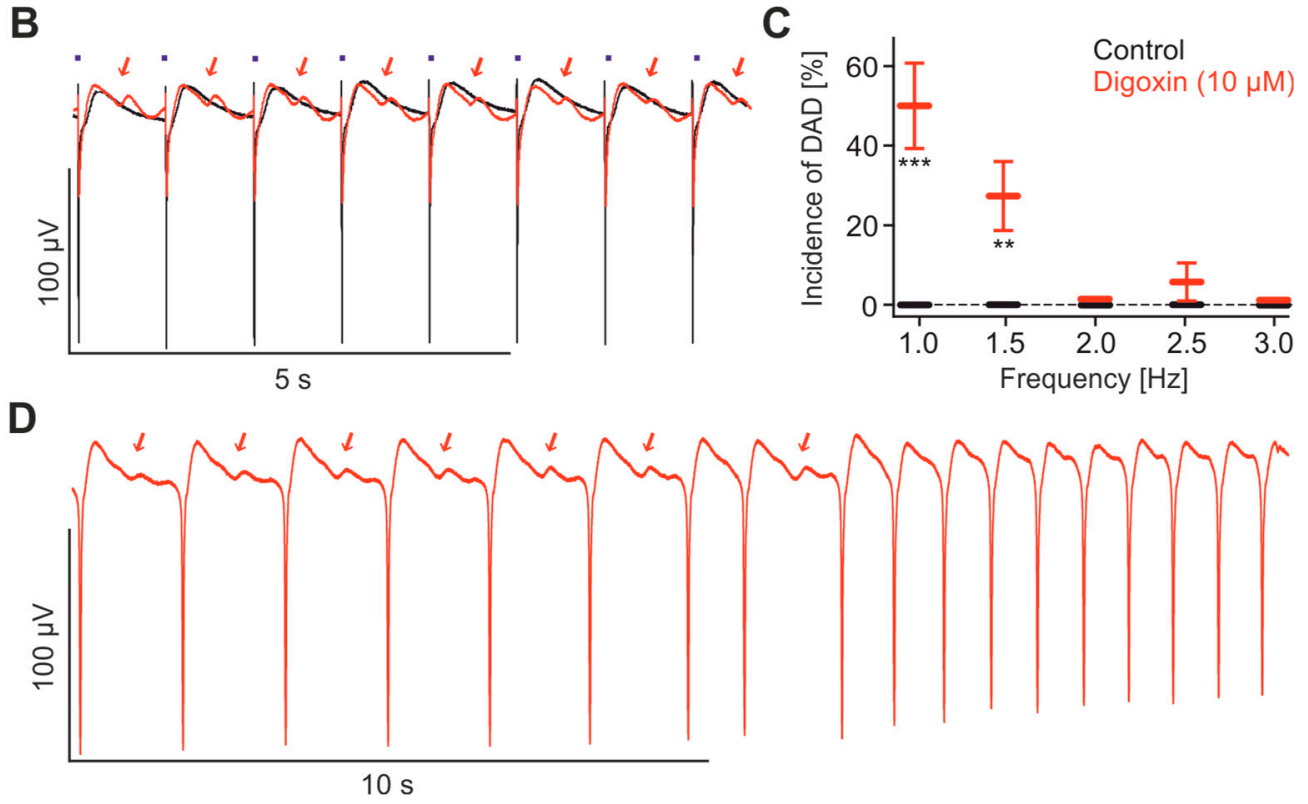

Figure 6. Effects of Digoxin. (A) Overlay of representative FP optically paced at $1 \mathrm{~Hz}$ (left) before (black) and after Digoxin application (red), and statistical analysis of the effects of $1 \mu \mathrm{M}$ and $10 \mu \mathrm{M}$ Digoxin on relative changes of max.DV (middle) and FPD (right) at the frequencies $1-3 \mathrm{~Hz}(n=10-11)$; (B) representative FP traces paced at $1 \mathrm{~Hz}$ in control conditions (black) and after application of $10 \mu \mathrm{M}$ Digoxin (red) with arrhythmic afterdepolarisations (red arrows); (C) statistical analysis of the incidence of afterdepolarisations at pacing rates of $1-3 \mathrm{~Hz}(n=15) ;(D)$ FP trace from a spontaneously beating monolayer the presence of $10 \mu \mathrm{M}$ Digoxin. Note the afterdepolarisations (red arrows) after each FP in the first phase (left) and the double beating rate in the second phase (right) indicating a FP triggering by each afterdepolarisation ${ }^{*} p<0.05,{ }^{* *} p<0.01,{ }^{* * *} p<0.001$.

\subsection{Xpress. $4 U^{T M}$ LightPace for Virus Free ChR2 Expression}

To avoid the virus-mediated gene transfer of ChR2 in hPSC-derived cardiomyocytes, which are difficult to transfect by standard methods, we took advantage of the commercially available Xpress. $4 \mathrm{U}^{\mathrm{TM}}$ LightPace kit (Ncardia). This method is based on special lipid particles containing mRNA for the expression of ChR2 and a C-terminal enhanced yellow fluorescent protein (EYFP)-tag. Already, $17 \mathrm{~h}$ after transfection, the expression of ChR2-EYFP was clearly detectable by fluorescence 
microscopy in over 70\% of cells in a confluent monolayer (Figure 7A). Adverse side effects from the transfection procedure or ChR2-EYFP expression could not be observed (Figure 7A). FACS analysis of dissociated cells quantified $79.9 \%$ EYFP positive cells, the same FACS setting detected $2.5 \%$ cells in untreated control cells (Figure 7B). In order to quantify the ChR2 function, Xpress4 $\mathrm{U}^{\mathrm{TM}}$ LightPace-treated cells were analysed using the patch clamp technology. We detected large light-induced inward currents (Figure 7C) with an average peak current of $17.9 \pm 2.0 \mathrm{pA} / \mathrm{pF}$ and a steady state current of $9.6 \pm 1.1 \mathrm{pA} / \mathrm{pF}$ (Figure 7D, $n=36$ ). The level of ChR2 expression was sufficient for optical pacing (Figure 7E) at $1.5 \mathrm{~Hz}$ using $10 \mathrm{~ms}$ long light pulses of $3.0 \mathrm{~mW} / \mathrm{mm}^{2}$ in $86.4 \%$ of cells $(n=38)$. Thus, the Xpress. $4 \mathrm{U}^{\mathrm{TM}}$ LightPace technology is well suited for functional ChR2 expression and is an easy to handle, non-viral and commercially available tool for the optogenetic pacing of hPSC-derived cardiomyocytes.

A

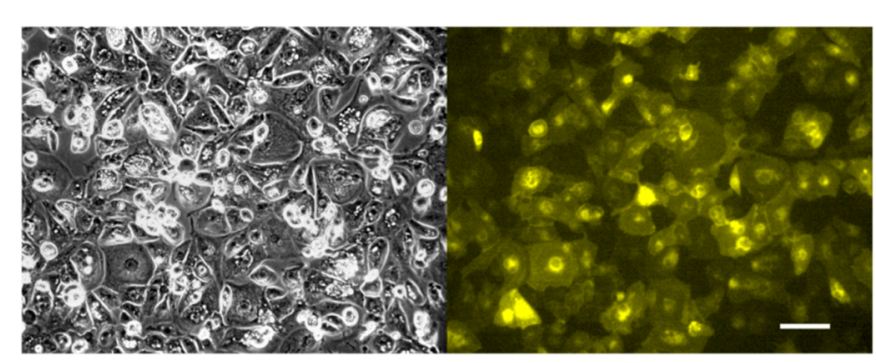

C

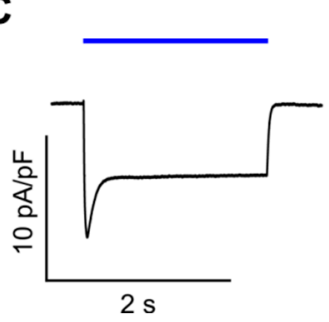

D

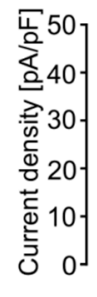

B

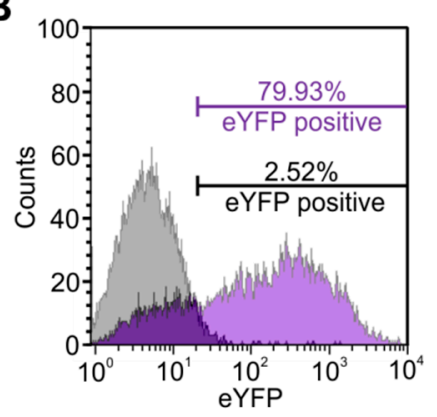

E

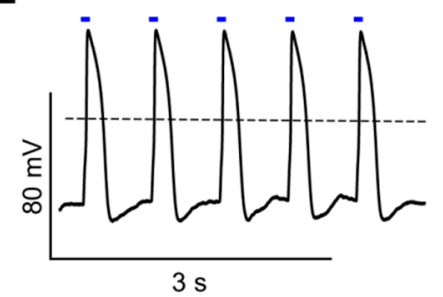

Figure 7. Characterisation of Xpress $4 \mathrm{U}^{\mathrm{TM}}$ LightPace transfected hPSC-derived Cor.4U ${ }^{\circledR}$ cardiomyocytes. (A) Phase contrast (left) and fluorescence enhanced yellow fluorescent protein (EYFP) image (right) $17 \mathrm{~h}$ after Xpress. $4 \mathrm{U}^{\mathrm{TM}}$ LightPace transfection (scale bar: $100 \mu \mathrm{m}$ ); (B) FACS analysis profile for ChR2-EYFP from Xpress4U ${ }^{\mathrm{TM}}$ LightPace transfected cells (purple) compared to non-infected control cells (grey); (C,D) light-induced $\left(3.0 \mathrm{~mW} / \mathrm{mm}^{2}\right)$ inward current at a holding potential of $-40 \mathrm{mV}$ in a Xpress $4 \mathrm{U}^{\mathrm{TM}}$ LightPace transfected cell (C) and statistics of ChR2 peak currents and steady state (SS) currents (D, $n=36$ cells); (E) representative trace of action potentials (APs) evoked by light pulses (10 $\mathrm{ms}, 3.0 \mathrm{~mW} / \mathrm{mm}^{2}$, blue bars).

\subsection{Future Trend and Automatisation with CardioExcyte96 SOL}

To demonstrate our approach with commercially available products and fully automated procedures, we developed the CardioExcyte96 SOL platform (Figure 8A,B) and integrated it into the existing CardioExcyteControl recording software. This new commercially available LED lid is based on the above-described prototype and enables precisely controlled light pulses at durations from 1 to $50 \mathrm{~ms}$ with a rise time $<40 \mu \mathrm{s}$, and a light intensity of $2.0 \mathrm{~mW} / \mathrm{mm}^{2}$ on each recording electrode (Figure $8 \mathrm{C}$ ). Thereby, the Xpress.4 $\mathrm{U}^{\mathrm{TM}}$ LightPace transfected hPSC-derived cardiomyocytes could be paced efficiently at beating rates from 1 to $2 \mathrm{~Hz}$. As proof of principle for automated cardiotoxicity screening, we tested the effect of Nifedipine with recording and analysis procedures performed by the CardioExcyteControl software. The workflow includes optical pacing and recording of evoked FP from 96 wells simultaneously (Figure 8D) and the subsequent automated analysis of max.DV and FPD (Figure 8E,F). The results showed reduction of max.DV and FPD by Nifedipine in a dose-dependent 
manner at all pacing frequencies (Figure 8G), similarly to the above-described and manually analysed results on AAV-transfected cardiomyocytes (Figure 4C).

A

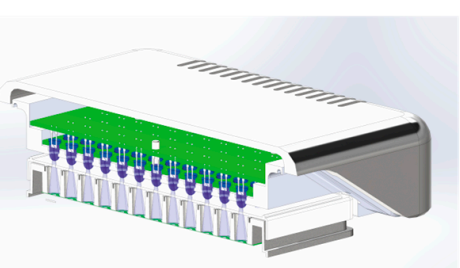

D

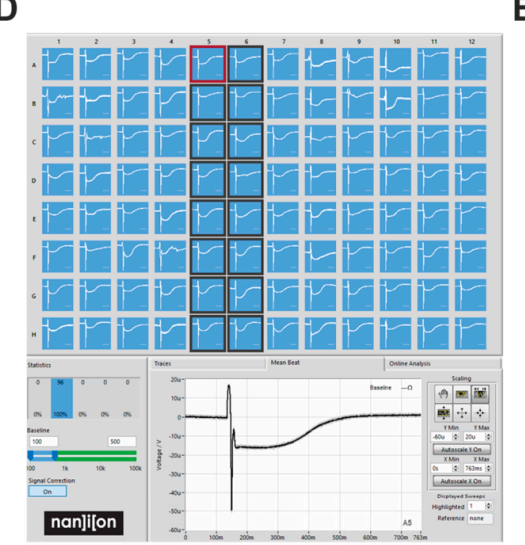

B

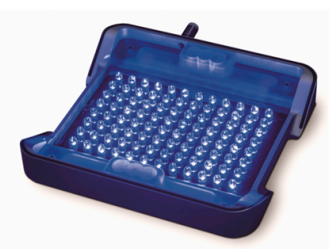

$\mathrm{E}$
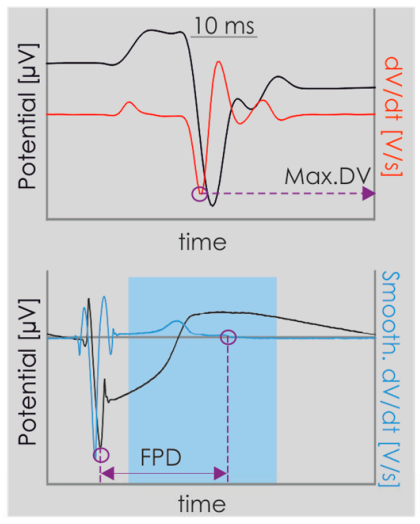

C

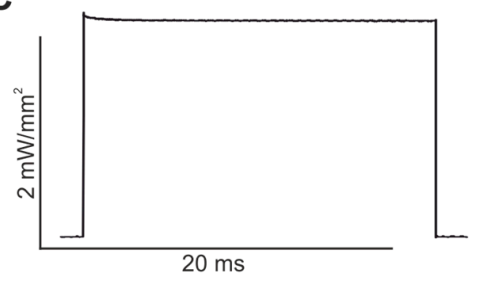

$\mathbf{F}$

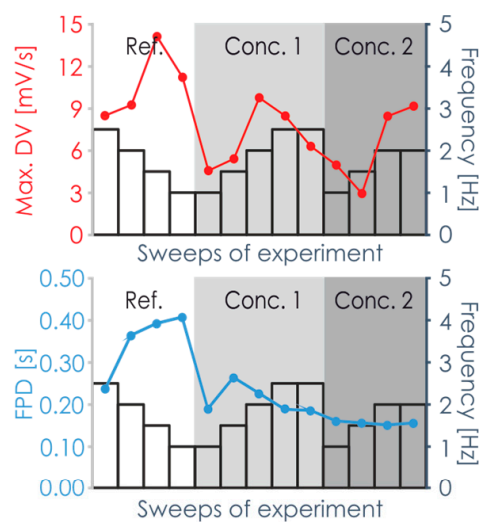

G

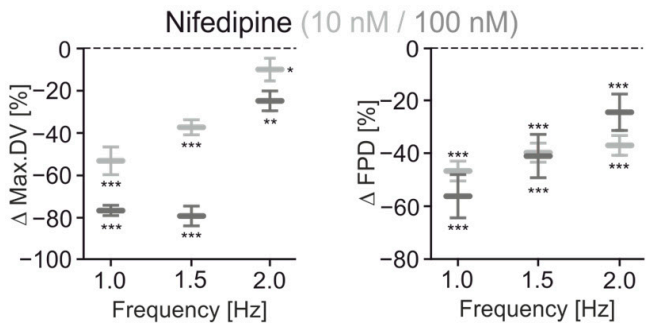

Figure 8. Automated FP recording and analysis of Xpress $4 \mathrm{U}^{\mathrm{TM}}$ LightPace transfected cells with CardioExcyte96 SOL platform. (A) Sketch of the CardioExcyte96 SOL with 96 LEDs integrated in the lid of a temperature controlled incubation system; (B) picture of the CardioExcyte96 SOL lid; (C) light intensity profile of a $20 \mathrm{~ms}$ light pulse from one LED at the level of recording electrodes; (D-F) workflow of the CardioExcyteControl analysis software; (D) screenshot showing optogenetically paced and averaged FP from all 96 wells; (E) description of automated analysis routines. For the max.DV parameter (E, top), the first derivative (red) is calculated from the first phase (60 ms window) of the FP (black) and its minimum (violet circle) is defined as max.DV. The FPD (E, lower) is defined from the minimal time point (first violet circle) in the FP signal (black) to the time point within a customizable analysis window (shaded blue) at which the smoothed first derivative (blue) is zero (second violet circle); (F) the values for max.DV (top) and FPD (bottom) are plotted for each recording episode with different pacing frequencies $(1-2 \mathrm{~Hz}$, indicated by bar graphs) and in different conditions ("Ref": baseline recordings, “Conc. 1": $10 \mathrm{nM}$ Nifedipine, “Conc. 2" = $100 \mathrm{nM}$ Nifedipine); (G) relative changes of max.DV and FPD by application of $10 \mathrm{nM}$ and $100 \mathrm{nM}$ Nifedipine $(n=16) .{ }^{*} p<0.05$, ${ }^{* *} p<0.01,{ }^{* * *} p<0.001$.

\section{Discussion}

In this report, we demonstrate that combining optogenetic stimulation with multi-well FP recordings from hPSC-derived cardiomyocytes enables fully automated cardiotoxicity screening. Importantly, our approach is based on simple, reproducible and easy-to-train protocols and all components are commercially available. We show two different strategies to express ChR2 in 
the hPSC-derived cardiomyocytes, which could be both parallelized by standard liquid handling robots. Gene transfer via AAV is very effective even when using tenfold lower virus titer in comparison to our earlier report [17] without decreased expression rate or reduced pacing efficiency. Importantly, expression was very stable over time and allowed optogenetic pacing even four weeks after transduction, which is in line with reliable AAV-based ChR2 gene transfer of mouse hearts in vivo more than one year after virus injection $[54,55]$. Therefore this approach will also allow to detect chronic effects of drugs, which promote arrhythmia only after long-term application, such as tyrosine kinase inhibitors used in cancer therapy and some hERG inhibitors also affecting the late $\mathrm{Na}^{+}$ current $[56,57]$. For such long-term experiments the new CardioExcyte96 SOL device is equipped with an incubator system which enables optogenetic pacing and FP recording at freely chosen intervals. For users who would like to circumvent virus handling, the new Xpress.4 $\mathrm{U}^{\mathrm{TM}}$ LightPace kit from Ncardia is an alternative. After a simple sonication step to generate fusogenic liposomes containing mRNA, this kit allows the expression of ChR2 in fusion with EYFP within hours after transfection of cells. In the future, the Xpress. $4 \mathrm{U}^{\mathrm{TM}}$ technology could also be used for other genetic modifications. Specifically for the cardiac arrhythmia field, CRISPR/Cas9-based induction or correction of single mutations [58] in combination with patient specific hPSC-derived cardiomyocytes would allow elegant studies investigating the effects of genetic Long QT, Short QT or Brugada syndromes.

In our report, cardiomyocytes expressing ChR2 using Xpress. $4 \mathrm{U}^{\mathrm{TM}}$ LightPace transfection required longer light pulses (10-20 ms) for reliable pacing than AAV-based ChR2 expression (1-2 ms) when using similar light intensities. Compared to our recent analysis of ChR2 mediated inward currents in AAV transduced hPSC-derived cardiomyocytes [17], we found in average comparable light-induced inward currents after expressing ChR2 using the Xpress.4U ${ }^{\mathrm{TM}} \mathrm{ChR} 2 \mathrm{mRNA}$ transfection, but also much higher variability between cells (Figure 7D). Because cardiomyocytes are electrically coupled through gap junctions when plated on MEA electrodes as a monolayer, the high variability of ChR2 current might explain the overall lower excitability of Xpress. $4 \mathrm{U}^{\mathrm{TM}}$ LightPace transfected cells. Importantly, both the AAV and the Xpress. $4 \mathrm{U}^{\mathrm{TM}}$ LightPace strategies allowed pacing with non-toxic low intensity light, which can be generated by standard LEDs. Importantly, the design of our initial custom-built LED lid and our analysis algorithms were integrated in a new commercially available optogenetic screening system, including a temperature-controlled LED lid with incubator function as well as an integrated FP recording and LED stimulation software (CardioExcyte96 SOL, Nanion Technologies).

The exact control of and measurement at a specific beating rate is very important in order to detect rate-dependent alterations of APD by drugs or mutations. Because of the limited range of spontaneous beating rates of hPSC-derived cardiomyocytes under physiological conditions as well as because of a possible modulation of the beating rate by applied drugs, rate-dependent effects could be missed when measuring only at spontaneous beating rates and correcting the FPD with non-validated $\mathrm{QT}_{\mathrm{c}}$ correction formulas [22,24,59]. Using optogenetic stimulation, the hERG channel blocker E4031 and the drug Sotalol showed the most FPD prolonging effect at lower heart rates. This is in accordance with the reverse use dependence of most hERG blockers [33], and with clinical studies on drug-induced Long QT syndromes reporting the induction of malignant Torsades de Pointes arrhythmia, especially at slow beating rates or by the first beat after a long post-extrasystolic pause [2].

We have previously shown that optogenetic pacing in vitro by global illumination results in a simultaneous activation of all cardiomyocytes and electrical activity without a conduction delay [17]. This advantage becomes evident when recording FP with large recording electrodes such as those in the CardioExcyte96 system with a $2 \mathrm{~mm}$ diameter. Due to the fact that, in our approach, one LED is illuminating the whole recording electrode, the simultaneous activation of all cardiomyocytes is physically averaged resulting reliably in one FP with the typical shape. The signal-to-noise ratio and thus quality of the FP recordings is dependent on the amount of cells from which the electrical activity can be recorded. In principle, our approach could be expanded to even larger electrodes as long as sufficient global illumination is feasible. The simultaneous activation is especially important for the 
initial component of the FP, because only one continuous and non-fragmented fast downstroke signal allows the analysis of the max.DV parameter, which reflects the fast $\mathrm{Na}^{+}$and $\mathrm{Ca}^{2+}$ current-based depolarisation during phase 0 of the cardiac AP. Thus optogenetic pacing of cardiomyocytes on large electrodes also enables drug screening for side effects slowing the AP depolarisation, either by directly blocking $\mathrm{Na}^{+}$or $\mathrm{Ca}^{2+}$ currents or indirectly by elevating the resting membrane potential leading to voltage-dependent inhibition of $\mathrm{Na}^{+}$currents. Because such effects are slowing electrical conduction and are therefore highly pro-arrhythmogenic, detecting drug action on the max.DV parameter adds great value to a cardiotoxicity screening system. Likewise, we detected not only the well-known effect of Sotalol on FP prolongation, but also its negative side effect on the AP depolarisation phase, which has previously been described [60,61].

The need for frequency-dependent drug screening becomes even more evident when analysing the effects of the $\mathrm{Na}^{+}$channel blocker Flecainide, which not only showed the expected reduction of the max.DV parameter but also prolonged the FP only at low beating rates. This was shown previously [62] and can be explained by blocking of hERG channels [63]. However, at a high pacing frequency, we detected a significant and concentration-dependent shortening of the FP. Together with the pronounced inhibitory effect on the max.DV parameter particularly at fast beating, this could be due to an inhibitory side effect on $\mathrm{Ca}^{2+}$ channels or due to a blocking effect on the late $\mathrm{Na}^{+}$current. In particular, the latter effect was discussed before to be more effective at higher rates [64] when hERG currents have less influence on repolarisation. In addition to the specific FPD and max.DV parameters, which can be considered as an indirect measure of pro-arrhythmogenic side effects of drugs, we were able to detect afterdepolarisation-like signals in FP recordings after treating cardiomyocytes with Digoxin, but only at low pacing rates. Because such events are likely to be a key trigger to induce a cardiac arrhythmia, this analysis adds another important and direct surrogate parameter for pro-arrhythmia drug screening, which is one of the main goals of the CiPA initiative [9].

\section{Materials and Methods}

\subsection{Cell Culture and AAV-Mediated Transduction}

For each batch a total of $1 \times 10^{6}$ hPSC-derived cardiomyocytes (Cor.4 $\mathrm{U}^{\circledR}$ cells, Ncardia) were ordered and delivered non-frozen in a T25 flask. On the day of arrival, the cells were transduced with 6550 genome copies/cell of AAV to express ChR2 (PennVector Core, University of Pennsylvania, PA, USA). We used the AAV 2.1 (AAV serotype 2 with capsid of serotype 1) with ChR2 in fusion with the fluorescence protein mCherry under control of the CAG-promotor for high expression in cardiomyocytes. After two days of incubation at $37^{\circ} \mathrm{C}$ and $5 \% \mathrm{CO}_{2}$ in Cor. $4 \mathrm{U}^{\circledR}$ medium, the cells were dissociated as reported previously [17]. In brief, the cells were incubated in the flask with TrypLE Express (Thermo Fisher Scientific, Hennef, Germany) at $37^{\circ} \mathrm{C}$ and $5 \% \mathrm{CO}_{2}$ for $4 \mathrm{~min}$. After adding of $10 \mathrm{~mL}$ of ice-cold Cor. $4 \mathrm{U}^{\circledR}$ medium, cells were detached and incubated at $4{ }^{\circ} \mathrm{C}$ for $20 \mathrm{~min}$ and then centrifuged at $700 \mathrm{rpm}$ for $4 \mathrm{~min}$ before being finally resuspended and used for downstream analysis.

\subsection{Determination of ChR2-Expression after $A A V$-Transduction}

For quantification of ChR2-expression three weeks after AAV-based gene transfer by FACS analysis, 100,000 transduced Cor. $4 \mathrm{U}^{\circledR}$ cells were plated per well in fibronectin-coated $(10 \mu \mathrm{g} / \mathrm{mL}$; Sigma Aldrich, Darmstadt, Germany) 24-well plates and cultured in Cor.4 $\mathrm{U}^{\circledR}$ medium (changed twice a week). After three weeks, cells were dissociated with $1 \mathrm{~mL}$ TrypLE Express dissolved in $1 \mathrm{~mL}$ phosphate-buffered saline (PBS) and analysed with a CyFlow Space FACS (Partec GmbH, Görlitz, Germany) equipped with a $561 \mathrm{~nm}$ laser for excitation and a $590 \pm 50 \mathrm{~nm}$ emission filter. Cells positive for mCherry were quantified by determining the gating setting using mCherry negative cells.

For immunostaining, cells were dissociated as above and plated on fibronectin coated cover glass and cultured for three weeks. After fixation with $4 \%$ paraformaldehyde (PFA), the cells were stained with primary antibodies against cardiac Troponin $\mathrm{T}$ (Abcam, Cambridge, UK) in $0.2 \%$ Triton 
$\mathrm{X}$ (Sigma Aldrich) and 5\% Donkey Serum for $1.5 \mathrm{~h}$ and Cy2-conjugated antibody against rabbit ImmunglobulinG (Thermo Fisher Scientific) for $1 \mathrm{~h}$ in Hoechst $(1 \mu \mathrm{g} / \mathrm{mL}$ in PBS). Microscope pictures were taken with an inverted fluorescence microscope (Axiovert $200 \mathrm{M}$, Zeiss, Oberkochen, Germany) using the Apotome section module, through a $40 \times$ Plan-Apochromat objective (Zeiss), mCherry (F46-008), Cy2 (HC 470-22ex, HC 495bs, HC 510/10em) filter sets (AHF Analysentechnik, Tübingen, Germany) and the AxioCam MRm camera with the AxioVision software (Version 4.8.2, Zeiss).

\subsection{CardioExcyte96 LED Setup and FP Recordings}

For FP recording, cardiomyocytes were plated directly on recording electrodes of CardioExcyte sensor plates (NSP-96, Nanion Technologies). For this purpose, cells were dissociated as described above, centrifuged and resuspended to obtain 20,000 cells per $2 \mu \mathrm{L}$ drop. Recording electrodes were coated with $2 \mu \mathrm{L}$ fibronectin $\left(10 \mu \mathrm{g} / \mathrm{mL}\right.$; Sigma Aldrich) for $30-45 \mathrm{~min}$ at $37^{\circ} \mathrm{C}$ and $5 \% \mathrm{CO}_{2}$. Subsequently the fibronectin solution was removed and a $2 \mu \mathrm{L}$ drop of the cell suspension was placed exactly on the recording electrode. After $45 \mathrm{~min}$ incubation at $37^{\circ} \mathrm{C}$ and $5 \% \mathrm{CO}_{2}$, the wells were gently filled with $300 \mu \mathrm{L}$ of Cor. $4 \mathrm{U}^{\circledR}$ medium. After plating locally on the recording electrode, the cardiomyocytes formed a confluent monolayer which started to beat spontaneously. Plates were incubated for three to four weeks at $37{ }^{\circ} \mathrm{C}$ and $5 \% \mathrm{CO}_{2}$. Twice a week, approximately two-thirds of the medium was exchanged to reduce sheer stress and to prevent cell loss.

FP were recorded from the CardioExcyte sensor plates with the CardioExcyte96 system (Nanion Technologies). For application of light pulses, a LED lid was custom built with 96 LEDs (470 nm, NSPB500AS, Nichia). LEDs were powered by constant current triggered LED drivers (LUMITRONIX, Hechingen, Germany) at $100 \mathrm{~mA}$. The light intensity was calibrated with a fast powermeter (PM100A with S170C sensor, Thorlabs, Newton, NJ, USA) placed at the level of the recording electrodes and a pinhole of the size of a recording electrode.

FP were recorded in $20 \mathrm{~s}$ long sweeps at $10 \mathrm{kHz}$ sampling rate at $35^{\circ} \mathrm{C}$ and $5 \% \mathrm{CO}_{2}$ in IMDM medium without FCS containing 1\% non-essential amino acids (Gibco, Thermo Fisher Scientific), $1 \%$ penicillin/streptomycin (Gibco, Thermo Fisher Scientific) and $0.1 \% \beta$-mercaptoethanol (Sigma Aldrich). After recording of baseline control signals, compounds were added in the indicated concentrations from stock solutions (Digoxin $1 \mathrm{mM}$ in MeOH, E4031 1 mM in Iscove's Modified Dulbecco's Media (IMDM), Isoprenaline $1 \mathrm{mM}$ in IMDM, Lidocaine $100 \mathrm{mM}$ in EtOH, Nifedipine $3 \mathrm{mM}$ in EtOH, Sotalol $10 \mathrm{mM}$ in IMDM).

\subsection{Analysis of FP}

All individual FP in the $20 \mathrm{~s}$ long recording sweeps were averaged using the time point and the frequency of LED stimulation as the averaging trigger. The max.DV parameter and the FPD were determined manually (Figures 2-6) using the Origin Pro 8G software (Version 8.0988, OriginLab, Northampton, MA, USA) or automatically with the CardioExcyteControl recording software (Figure 8). Some wells showed inverted FP signals with a fast positive initial component and negative repolarisation wave, and these data were inverted before subsequent analysis. The max.DV parameter was defined as the most negative value of the first derivative of the FP. For determining the FPD, the delay from the first negative spike of the FP to the time point at which the smoothed (Savitzky-Golay filter, polynumeric order $=2$, window $=500$ data points) first derivative of the FP was zero (see also Figure 8E). Afterdepolarisations were defined as clearly visible negative deflections occurring in the repolarisation phase of the FP and quantified in non-averaged recording sweeps by calculation of the percentage of FP with afterdepolarisations.

\subsection{Determination of ChR2-Expression in Xpress. $4 U^{T M}$ LightPace Transfected Cor. $4 U^{\circledR}$ Cells}

Cor. $4 \mathrm{U}^{\circledR}$ cells were seeded on Geltrex-coated T-25 flasks $\left(1 \times 10^{6}\right.$ cells/flask $)$ and cultured for three days in Cor. $4 \mathrm{U}^{\circledR}$ medium (changed daily). On day 3, cells were transfected using the Xpress. $4 \mathrm{U}^{\mathrm{TM}}$ LightPace kit for ChR2 expression (Ncardia) according to the manufacturer's instructions. Then, $17 \mathrm{~h}$ 
after transfection, microscopic images were acquired using an epifluorescence microscope (Axiovert 200M, Zeiss), equipped with a 10× Achroplan (Ph1, NA 0.25, Zeiss), a YFP filter set (F41-028, AHF Analysetechnik), a HBO 100 mercury arc lamp and a 1.4 MP cooled digital camera (SPOT Pursuit, Diagnostics Instruments Inc., Burroughs, MI, USA). After image acquisition, cells were detached from T-25 flasks by Trypsin/Ethylenediaminetetraacetic acid (EDTA) (Sigma Aldrich) treatment for 5 min at $37^{\circ} \mathrm{C}$ and centrifuged at $200 \times g$ for $5 \mathrm{~min}$. Cell pellets were resuspended in PBS containing $2 \%$ fetal calf serum (FCS) and filtered with a $40 \mu \mathrm{m}$ cell strainer to obtain a uniform single-cell suspension for flow cytometric analyses (BD FACS Calibur, BD Biosciences, Singapore) equipped with $488 \mathrm{~nm}$ argon laser for excitation and a 530/30 nm FL1 emission filter.

\subsection{Patch Clamp Analysis of Xpress. $4 U^{T M}$ LightPace Transfected Cor. $4 U^{\circledR}$ Cells}

For patch clamp analysis, Cor. $4 \mathrm{U}^{\circledR}$ cells were seeded in a T-25 flask and transfected with the Xpress. $4 \mathrm{U}^{\mathrm{TM}}$ LightPace kit for ChR2 expression (Ncardia) in $2 \mathrm{~mL}$ volume for $30 \mathrm{~min}$ at $37^{\circ} \mathrm{C}$ accordingly to the manufacturer's instructions. Cor. $4 \mathrm{U}^{\circledR}$ medium was added and cells were incubated for $8 \mathrm{~h}$. Subsequently cells were dissociated from the T-25 flask as described above and replated at low densities on fibronectin-coated $(10 \mu \mathrm{g} / \mathrm{mL})$ coverslips. Patch clamp experiments were performed two to three days after mRNA transfection in the whole cell configuration using an EPC 10 amplifier (HEKA Elektronik, Ludwigshafen, Germany). The internal solution contained (in mmol/L) $50 \mathrm{KCl}, 80 \mathrm{~K}$-Aspartate, $1 \mathrm{MgCl}_{2}, 3 \mathrm{MgATP}, 10$ Ethylene-bis(oxyethylenenitrilo)tetraacetic acid (EGTA), 10 4-(2-Hydroxyethyl)piperazine-1-ethanesulfonic acid, $N$-(2-Hydroxyethyl) piperazine- $\mathrm{N}^{\prime}$-(2-ethanesulfonic acid) (HEPES), pH $7.2(\mathrm{KOH})$ and the external solution $140 \mathrm{NaCl}$, $5.4 \mathrm{KCl}, 1.8 \mathrm{CaCl}_{2}, 1 \mathrm{MgCl}_{2}, 10$ HEPES, 10 Glucose, $\mathrm{pH} 7.4(\mathrm{NaOH})$. Cells were stimulated with blue light $(470 \mathrm{~nm})$ from a LED module (LEDHUB, Omicron Laserage, Rodgau, Germany) coupled to the epifluorescence port of an Axiovert 200 microscope (Zeiss) and controlled by the EPC 10 amplifier. Light-induced currents were characterised in the voltage clamp mode at a holding potential of $-40 \mathrm{mV}$ with supramaximal light stimulation of $3.0 \mathrm{~mW} / \mathrm{mm}^{2}$ for $2 \mathrm{~s}$. Peak currents were analysed by determining the maximal inward current and the steady-state current was averaged between 1320 to $1920 \mathrm{~ms}$ after start of the light pulse using Fitmaster (HEKA Elektronik). AP were recorded in the current clamp mode and were elicited by $10 \mathrm{~ms}$-long blue light pulses $(470 \mathrm{~nm})$ at increasing light intensities $\left(0-3 \mathrm{~mW} / \mathrm{mm}^{2}\right)$. Light stimulation was repeated five times at a frequency of $1.5 \mathrm{~Hz}$, and the minimal light intensity for $100 \%$ AP generation was determined.

\subsection{FP Recordings of Xpress.4U $U^{T M}$ LightPace Transfected Cor. $4 U^{\circledR}$ Cells with the CardioExcyte96 SOL System}

For FP recording, 30,000 wild-type Cor. $4 \mathrm{U}^{\circledR}$ cells were plated on CardioExcyte sensor plates as described above and transfected at day 10 with the Xpress. $4 \mathrm{U}^{\mathrm{TM}}$ LightPace kit for ChR2 expression (50 $\mu \mathrm{L}$ final volume per well of the CardioExcyte sensor plate) for $30 \mathrm{~min}$ at $37^{\circ} \mathrm{C}$. Recording of optogenetically paced FP was performed two days after mRNA transfection on the commercially available CardioExcyte96 SOL system (Nanion Technologies). The light intensity of the CardioExcyte96 SOL was determined, as described above. Automated analysis of max.DV and FPD was performed with CardioExcyteControl software as described above (see also Figure $8 \mathrm{D}$ and its legend). The analysis window to determine FPD is customizable as a fraction of the inter-beat interval (1/pacing rate) to account for different FP shapes and the frequency-dependent FPD.

\subsection{Statistical Analysis}

All data is shown as mean \pm SEM. Values of max.DV and FPD are either presented as absolute values (Figures 2 and $3 C, D$ ) or as the percent change normalized to control conditions without drug application (Figures 3E, 4, 5, 6 and 8). Statistical analysis on drug effects was performed with two-sided paired student's $t$-test by comparing FP parameters in the presence of drugs to baseline conditions for each pacing frequency individually. The FP alteration over time (Figure 2) and the 
frequency dependence of FP parameters (Figure 3C,D) were analysed with one-way ANOVA repeated measurements and Dunnett's post-test. A $p$ value of $<0.05$ was considered statistically significant and the n-values are indicating the number of independent wells of the CardioExcyte sensor plates. Statistical analysis was performed using GraphPad Prism (Version 5.01, GraphPad Software, La Jolla, CA, USA).

\section{Conclusions}

We herein present a fully automated approach, which enables frequency dependent cardiotoxicity screening in a scalable 96-well format. Importantly, the CardioExcyte96 SOL optogenetic drug screening system is available as an all-in-one tool including the software needed for automated recording and analysis (Figure 8). Our approach allows the determination of rate-dependent side effects of drugs on $\mathrm{K}^{+}, \mathrm{Na}^{+}$and $\mathrm{Ca}^{2+}$ channels as surrogate parameters for cardiac arrhythmia propensity and therefore represents an important step towards scalable cardiotoxicity screening and will increase safety and effectiveness of drug screening in the pharmaceutical industry.

Acknowledgments: We thank Frank Holst (University Bonn) for the technical assistance, Niels Fertig, Sonja Stölzle-Feix and Michael George (Nanion Technologies) for helpful discussion. This work was supported by the German Federal Ministry of Education and Research (BMBF) through the EuroTransBio project "OPTEL" (031B0080B), the German Research Foundation (SA-1785/7-1, SA-1785/9-1 and Research Training Group 1873), the German Heart Foundation and the BONFOR Program, Medical Faculty, University of Bonn.

Author Contributions: Susanne Rehnelt, Matthias Beckler, Ralf Kettenhofen, Heribert Bohlen, Tobias Bruegmann and Philipp Sasse conceived and designed the experiments; Susanne Rehnelt, Daniela Malan, Leo Doerr, Benjamin Wolters and Krisztina Juhasz performed the experiments; Susanne Rehnelt, Daniela Malan, Leo Doerr and Tobias Bruegmann analysed the data; Susanne Rehnelt, Daniela Malan, Tobias Bruegmann and Philipp Sasse wrote the paper with input from all authors.

Conflicts of Interest: Leo Doerr, Krisztina Juhasz and Matthias Beckler are employees of Nanion Technologies $\mathrm{GmbH}$ which developed the CardioExcyte96 SOL lid discussed in the manuscript. Benjamin Wolters, Ralf Kettenhofen and Heribert Bohlen are employees of Axiogenesis AG part of the Ncardia Group, which developed the Xpress. $4 \mathrm{U}^{\mathrm{TM}}$ technology discussed in the manuscript. The authors declare that the research was conducted in the absence of any commercial or financial relationships that could be construed as a potential conflict of interest.

$\begin{array}{ll}\text { Abbreviations } \\ \text { AAV } & \text { adeno-associated virus } \\ \text { AP } & \text { action potential } \\ \text { APD } & \text { action potential duration } \\ \text { CAG } & \text { chicken } \beta \text { actin } \\ \text { ChR2 } & \text { Channelrhodopsin-2 } \\ \text { CiPA } & \text { comprehensive in vitro proarrhythmia assay } \\ \text { ECG } & \text { electrocardiogram } \\ \text { EDTA } & \text { Ethylenediaminetetraacetic acid } \\ \text { EGTA } & \text { Ethylene-bis(oxyethylenenitrilo)tetraacetic acid } \\ \text { EYFP } & \text { enhanced yellow fluorescent protein } \\ \text { FACS } & \text { fluorescence-activated cell sorting } \\ \text { FCS } & \text { fetal calf serum } \\ \text { FP } & \text { field potential }\end{array}$




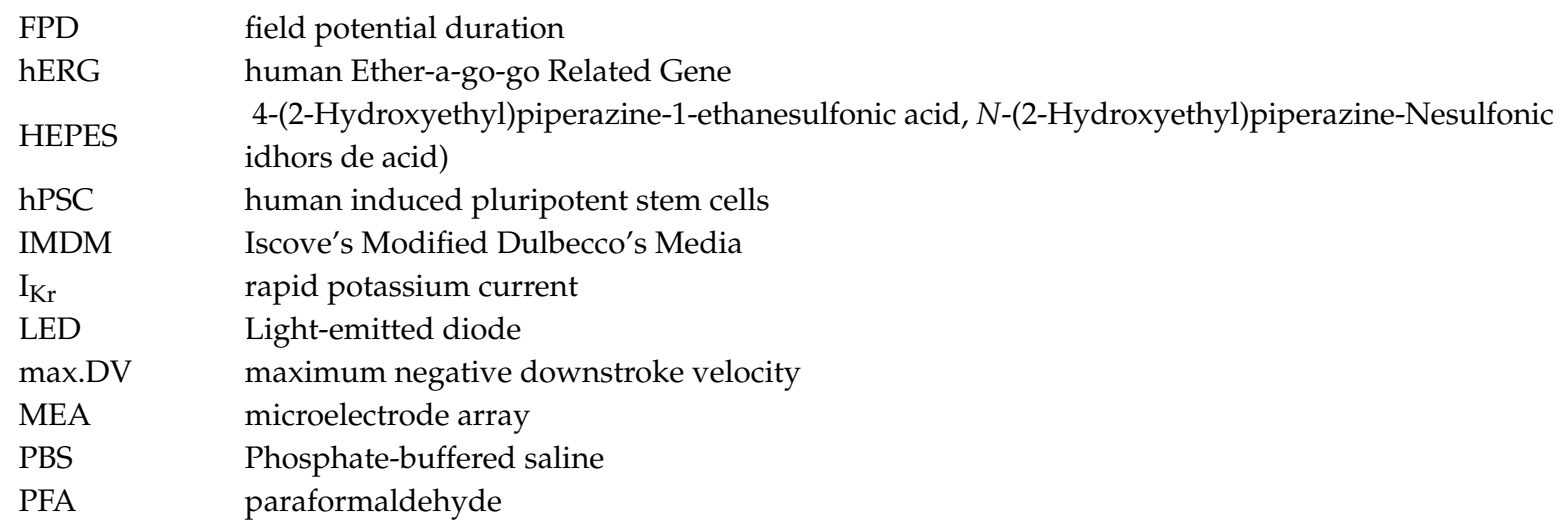

\section{References}

1. Onakpoya, I.J.; Heneghan, C.J.; Aronson, J.K. Post-marketing withdrawal of 462 medicinal products because of adverse drug reactions: A systematic review of the world literature. BMC Med. 2016, 14. [CrossRef] [PubMed]

2. Kannankeril, P.; Roden, D.M.; Darbar, D. Drug-induced long QT syndrome. Pharmacol. Rev. 2010, 62, 760-781. [CrossRef] [PubMed]

3. Ferri, N.; Siegl, P.; Corsini, A.; Herrmann, J.; Lerman, A.; Benghozi, R. Drug attrition during pre-clinical and clinical development: Understanding and managing drug-induced cardiotoxicity. Pharmacol. Ther. 2013, 138, 470-484. [CrossRef] [PubMed]

4. Kannankeril, P.J.; Roden, D.M. Drug-induced long QT and torsade de pointes: Recent advances. Curr. Opin. Cardiol. 2007, 22, 39-43. [CrossRef] [PubMed]

5. Navarrete, E.G.; Liang, P.; Lan, F.; Sanchez-Freire, V.; Simmons, C.; Gong, T.; Sharma, A.; Burridge, P.W.; Patlolla, B.; Lee, A.S.; et al. Screening drug-induced arrhythmia using human induced pluripotent stem cell-derived cardiomyocytes and low-impedance microelectrode arrays. Circulation 2013, 128, S3-S13. [CrossRef] [PubMed]

6. Meyer, T.; Leisgen, C.; Gonser, B.; Gunther, E. QT-screen: High-throughput cardiac safety pharmacology by extracellular electrophysiology on primary cardiac myocytes. Assay Drug Dev. Technol. 2004, 2, 507-514. [CrossRef] [PubMed]

7. ICH.S7b, the Nonclinical Evaluation of the Potential for Delayed Ventricular Repolarization (Qt Prolongation) by Human Pharmaceuticals. 2005. Available online: http://www.ich.org/fileadmin/Public_Web_Site/ICH_ Products/Guidelines/Safety/S7B/Step4/S7B_Guideline.pdf (accessed on 10 August 2017).

8. Meyer, T.; Sartipy, P.; Blind, F.; Leisgen, C.; Guenther, E. New cell models and assays in cardiac safety profiling. Expert Opin. Drug Metab. Toxicol. 2007, 3, 507-517. [CrossRef] [PubMed]

9. Sager, P.T.; Gintant, G.; Turner, J.R.; Pettit, S.; Stockbridge, N. Rechanneling the cardiac proarrhythmia safety paradigm: A meeting report from the Cardiac Safety Research Consortium. Am. Heart J. 2014, 167, 292-300. [CrossRef] [PubMed]

10. Konstantopoulou, A.; Tsikrikas, S.; Asvestas, D.; Korantzopoulos, P.; Letsas, K.P. Mechanisms of drug-induced proarrhythmia in clinical practice. World J. Cardiol. 2013, 5, 175-185. [CrossRef] [PubMed]

11. De Ponti, F.; Poluzzi, E.; Cavalli, A.; Recanatini, M.; Montanaro, N. Safety of non-antiarrhythmic drugs that prolong the QT interval or induce torsade de pointes: An overview. Drug Saf. 2002, 25, 263-286. [CrossRef] [PubMed]

12. Ebert, A.D.; Liang, P.; Wu, J.C. Induced pluripotent stem cells as a disease modeling and drug screening platform. J. Cardiovasc. Pharmacol. 2012, 60, 408-416. [CrossRef] [PubMed]

13. Mordwinkin, N.M.; Burridge, P.W.; Wu, J.C. A review of human pluripotent stem cell-derived cardiomyocytes for high-throughput drug discovery, cardiotoxicity screening, and publication standards. J. Cardiovasc. Transl. Res. 2013, 6, 22-30. [CrossRef]

14. Belles, B.; Malecot, C.O.; Hescheler, J.; Trautwein, W. "Run-down" of the Ca current during long whole-cell recordings in guinea pig heart cells: Role of phosphorylation and intracellular calcium. Pflugers Arch. 1988, 411, 353-360. [CrossRef] [PubMed] 
15. Meyer, T.; Boven, K.H.; Gunther, E.; Fejtl, M. Micro-electrode arrays in cardiac safety pharmacology: A novel tool to study QT interval prolongation. Drug Saf. 2004, 27, 763-772. [CrossRef] [PubMed]

16. Halbach, M.; Egert, U.; Hescheler, J.; Banach, K. Estimation of action potential changes from field potential recordings in multicellular mouse cardiac myocyte cultures. Cell. Physiol. Biochem. 2003, 13, 271-284. [CrossRef] [PubMed]

17. Lapp, H.; Bruegmann, T.; Malan, D.; Friedrichs, S.; Kilgus, C.; Heidsieck, A.; Sasse, P. Frequency-dependent drug screening using optogenetic stimulation of human iPSC-derived cardiomyocytes. Sci. Rep. 2017, 7, 9629. [CrossRef] [PubMed]

18. Qu, Y.; Vargas, H.M. Proarrhythmia Risk Assessment in Human Induced Pluripotent Stem Cell-Derived Cardiomyocytes Using the Maestro MEA Platform. Toxicol. Sci. 2015, 147, 286-295. [CrossRef] [PubMed]

19. Kuusela, J.; Kujala, V.J.; Kiviaho, A.; Ojala, M.; Swan, H.; Kontula, K.; Aalto-Setala, K. Effects of cardioactive drugs on human induced pluripotent stem cell derived long QT syndrome cardiomyocytes. Springerplus 2016, 5, 234. [CrossRef] [PubMed]

20. Kitaguchi, T.; Moriyama, Y.; Taniguchi, T.; Ojima, A.; Ando, H.; Uda, T.; Otabe, K.; Oguchi, M.; Shimizu, S.; Saito, H.; et al. CSAHi study: Evaluation of multi-electrode array in combination with human iPS cell-derived cardiomyocytes to predict drug-induced QT prolongation and arrhythmia-Effects of 7 reference compounds at 10 facilities. J. Pharmacol. Toxicol. Methods 2016, 78, 93-102. [CrossRef] [PubMed]

21. Kaneko, T.; Nomura, F.; Hamada, T.; Abe, Y.; Takamori, H.; Sakakura, T.; Takasuna, K.; Sanbuissho, A.; Hyllner, J.; Sartipy, P.; et al. On-chip in vitro cell-network pre-clinical cardiac toxicity using spatiotemporal human cardiomyocyte measurement on a chip. Sci. Rep. 2014, 4, 4670. [CrossRef] [PubMed]

22. Harris, K.; Aylott, M.; Cui, Y.; Louttit, J.B.; McMahon, N.C.; Sridhar, A. Comparison of electrophysiological data from human-induced pluripotent stem cell-derived cardiomyocytes to functional preclinical safety assays. Toxicol. Sci. 2013, 134, 412-426. [CrossRef] [PubMed]

23. Gilchrist, K.H.; Lewis, G.F.; Gay, E.A.; Sellgren, K.L.; Grego, S. High-throughput cardiac safety evaluation and multi-parameter arrhythmia profiling of cardiomyocytes using microelectrode arrays. Toxicol. Appl. Pharmacol. 2015, 288, 249-257. [CrossRef] [PubMed]

24. Clements, M.; Thomas, N. High-throughput multi-parameter profiling of electrophysiological drug effects in human embryonic stem cell derived cardiomyocytes using multi-electrode arrays. Toxicol. Sci. 2014, 140, 445-461. [CrossRef] [PubMed]

25. Clements, M.; Millar, V.; Williams, A.S.; Kalinka, S. Bridging Functional and Structural Cardiotoxicity Assays Using Human Embryonic Stem Cell-Derived Cardiomyocytes for a More Comprehensive Risk Assessment. Toxicol. Sci. 2015, 148, 241-260. [CrossRef] [PubMed]

26. Braam, S.R.; Tertoolen, L.; van de Stolpe, A.; Meyer, T.; Passier, R.; Mummery, C.L. Prediction of drug-induced cardiotoxicity using human embryonic stem cell-derived cardiomyocytes. Stem Cell Res. 2010, 4, 107-116. [CrossRef] [PubMed]

27. Klimas, A.; Ambrosi, C.M.; Yu, J.; Williams, J.C.; Bien, H.; Entcheva, E. OptoDyCE as an automated system for high-throughput all-optical dynamic cardiac electrophysiology. Nat. Commun. 2016, 7, 11542. [CrossRef] [PubMed]

28. Hortigon-Vinagre, M.P.; Zamora, V.; Burton, F.L.; Green, J.; Gintant, G.A.; Smith, G.L. The Use of Ratiometric Fluorescence Measurements of the Voltage Sensitive Dye Di-4-ANEPPS to Examine Action Potential Characteristics and Drug Effects on Human Induced Pluripotent Stem Cell-Derived Cardiomyocytes. Toxicol. Sci. 2016, 154, 320-331. [CrossRef] [PubMed]

29. Dempsey, G.T.; Chaudhary, K.W.; Atwater, N.; Nguyen, C.; Brown, B.S.; McNeish, J.D.; Cohen, A.E.; Kralj, J.M. Cardiotoxicity screening with simultaneous optogenetic pacing, voltage imaging and calcium imaging. J. Pharmacol. Toxicol. Methods 2016, 81, 240-250. [CrossRef] [PubMed]

30. Doerr, L.; Thomas, U.; Guinot, D.R.; Bot, C.T.; Stoelzle-Feix, S.; Beckler, M.; George, M.; Fertig, N. New Easy-to-Use Hybrid System for Extracellular Potential and Impedance Recordings. J. Lab. Autom. 2014. [CrossRef] [PubMed]

31. Wagenaar, D.A.; Potter, S.M. Real-time multi-channel stimulus artifact suppression by local curve fitting. J. Neurosci. Methods 2002, 120, 113-120. [CrossRef]

32. Merrill, D.R.; Bikson, M.; Jefferys, J.G. Electrical stimulation of excitable tissue: Design of efficacious and safe protocols. J. Neurosci. Methods 2005, 141, 171-198. [CrossRef] [PubMed] 
33. Hondeghem, L.M.; Snyders, D.J. Class III antiarrhythmic agents have a lot of potential but a long way to go. Reduced effectiveness and dangers of reverse use dependence. Circulation 1990, 81, 686-690. [CrossRef] [PubMed]

34. Schwartz, P.J.; Priori, S.G.; Spazzolini, C.; Moss, A.J.; Vincent, G.M.; Napolitano, C.; Denjoy, I.; Guicheney, P.; Breithardt, G.; Keating, M.T.; et al. Genotype-phenotype correlation in the long-QT syndrome: Gene-specific triggers for life-threatening arrhythmias. Circulation 2001, 103, 89-95. [CrossRef] [PubMed]

35. Cerrone, M.; Priori, S.G. Genetics of sudden death: Focus on inherited channelopathies. Eur. Heart J. 2011, 32, 2109-2118. [CrossRef] [PubMed]

36. Nunes, S.S.; Miklas, J.W.; Liu, J.; Aschar-Sobbi, R.; Xiao, Y.; Zhang, B.; Jiang, J.; Masse, S.; Gagliardi, M.; Hsieh, A.; et al. Biowire: A platform for maturation of human pluripotent stem cell-derived cardiomyocytes. Nat. Methods 2013, 10, 781-787. [CrossRef] [PubMed]

37. Lieu, D.K.; Fu, J.D.; Chiamvimonvat, N.; Tung, K.C.; McNerney, G.P.; Huser, T.; Keller, G.; Kong, C.W.; Li, R.A. Mechanism-based facilitated maturation of human pluripotent stem cell-derived cardiomyocytes. Circ. Arrhythm. Electrophysiol. 2013, 6, 191-201. [CrossRef] [PubMed]

38. Herron, T.J.; Rocha, A.M.; Campbell, K.F.; Ponce-Balbuena, D.; Willis, B.C.; Guerrero-Serna, G.; Liu, Q.; Klos, M.; Musa, H.; Zarzoso, M.; et al. Extracellular Matrix-Mediated Maturation of Human Pluripotent Stem Cell-Derived Cardiac Monolayer Structure and Electrophysiological Function. Circ. Arrhythm. Electrophysiol. 2016, 9, e003638. [CrossRef] [PubMed]

39. Nagel, G.; Szellas, T.; Huhn, W.; Kateriya, S.; Adeishvili, N.; Berthold, P.; Ollig, D.; Hegemann, P.; Bamberg, E. Channelrhodopsin-2, a directly light-gated cation-selective membrane channel. Proc. Natl. Acad. Sci. USA 2003, 100, 13940-13945. [CrossRef] [PubMed]

40. Zhu, H.; Scharnhorst, K.S.; Stieg, A.Z.; Gimzewski, J.K.; Minami, I.; Nakatsuji, N.; Nakano, H.; Nakano, A. Two dimensional electrophysiological characterization of human pluripotent stem cell-derived cardiomyocyte system. Sci. Rep. 2017, 7, 43210. [CrossRef] [PubMed]

41. O'Hara, T.; Rudy, Y. Quantitative comparison of cardiac ventricular myocyte electrophysiology and response to drugs in human and nonhuman species. Am. J. Physiol. Heart Circ. Physiol. 2012, 302, H1023-H1030. [CrossRef] [PubMed]

42. Seed, W.A.; Noble, M.I.; Oldershaw, P.; Wanless, R.B.; Drake-Holland, A.J.; Redwood, D.; Pugh, S.; Mills, C. Relation of human cardiac action potential duration to the interval between beats: Implications for the validity of rate corrected QT interval (QTc). Heart J. 1987, 57, 32-37. [CrossRef]

43. Yokoo, N.; Baba, S.; Kaichi, S.; Niwa, A.; Mima, T.; Doi, H.; Yamanaka, S.; Nakahata, T.; Heike, T. The effects of cardioactive drugs on cardiomyocytes derived from human induced pluripotent stem cells. Biochem. Biophys. Res. Commun. 2009, 387, 482-488. [CrossRef] [PubMed]

44. Brown, J.; Marshall, R.J.; Winslow, E. Effects of selective channel blocking agents on contractions and action potentials in $\mathrm{K}^{+}$-depolarized guinea-pig atria. Br. J. Pharmacol. 1985, 86, 7-17. [CrossRef] [PubMed]

45. Asakura, K.; Hayashi, S.; Ojima, A.; Taniguchi, T.; Miyamoto, N.; Nakamori, C.; Nagasawa, C.; Kitamura, T.; Osada, T.; Honda, Y.; et al. Improvement of acquisition and analysis methods in multi-electrode array experiments with iPS cell-derived cardiomyocytes. J. Pharmacol. Toxicol. Methods 2015, 75, 17-26. [CrossRef] [PubMed]

46. Kamiya, K.; Niwa, R.; Mitcheson, J.S.; Sanguinetti, M.C. Molecular determinants of HERG channel block. Mol. Pharmacol. 2006, 69, 1709-1716. [CrossRef] [PubMed]

47. Iwamura, T.; Aoshima, J. A compilation of analytical data from inhibition studies on DNA polymerases and some of its implications. J. Biochem. 1985, 97, 1101-1110. [CrossRef] [PubMed]

48. Rosen, M.R. Cellular electrophysiology of digitalis toxicity. J. Am. Coll. Cardiol. 1985, 5, 22A-34A. [CrossRef]

49. Saner, H.E.; Lange, H.W.; Pierach, C.A.; Aeppli, D.M. Relation between serum digoxin concentration and the electrocardiogram. Clin. Cardiol. 1988, 11, 752-756. [CrossRef] [PubMed]

50. Ahnve, S. QT interval prolongation in acute myocardial infarction. Eur. Heart J. 1985, 6, 85-95. [CrossRef] [PubMed]

51. Guo, L.; Qian, J.Y.; Abrams, R.; Tang, H.M.; Weiser, T.; Sanders, M.J.; Kolaja, K.L. The electrophysiological effects of cardiac glycosides in human iPSC-derived cardiomyocytes and in guinea pig isolated hearts. Cell. Physiol. Biochem. 2011, 27, 453-462. [CrossRef] [PubMed] 
52. Koh, C.H.; Wu, J.; Chung, Y.Y.; Liu, Z.; Zhang, R.R.; Chong, K.; Korzh, V.; Ting, S.; Oh, S.; Shim, W.; et al. Erratum: Identification of $\mathrm{Na}^{+} / \mathrm{K}^{+}$-ATPase inhibition-independent proarrhythmic ionic mechanisms of cardiac glycosides. Sci. Rep. 2017, 7, 11498. [CrossRef] [PubMed]

53. Xie, J.T.; Cunningham, P.M.; January, C.T. Digoxin-induced delayed afterdepolarizations: Biphasic effects of digoxin on action potential duration and the Q-T interval in cardiac Purkinje fibers. Methods Find. Exp. Clin. Pharmacol. 1995, 17, 113-120. [PubMed]

54. Bruegmann, T.; Boyle, P.M.; Vogt, C.C.; Karathanos, T.V.; Arevalo, H.J.; Fleischmann, B.K.; Trayanova, N.A.; Sasse, P. Optogenetic defibrillation terminates ventricular arrhythmia in mouse hearts and human simulations. J. Clin. Investig. 2016, 126, 3894-3904. [CrossRef] [PubMed]

55. Vogt, C.C.; Bruegmann, T.; Malan, D.; Ottersbach, A.; Roell, W.; Fleischmann, B.K.; Sasse, P. Systemic gene transfer enables optogenetic pacing of mouse hearts. Cardiovasc. Res. 2015, 106, 338-343. [CrossRef] [PubMed]

56. Lu, Z.J.; Wu, C.Y.C.; Jiang, Y.P.; Ballou, L.M.; Clausen, C.; Cohen, I.S.; Lin, R.Z. Suppression of Phosphoinositide 3-Kinase Signaling and Alteration of Multiple Ion Currents in Drug-Induced Long QT Syndrome. Sci. Transl. Med. 2012, 4, 131ra50. [CrossRef] [PubMed]

57. Yang, T.; Chun, Y.W.; Stroud, D.M.; Mosley, J.D.; Knollmann, B.C.; Hong, C.; Roden, D.M. Screening for Acute I-Kr Block Is Insufficient to Detect Torsades de Pointes Liability Role of Late Sodium Current. Circulation 2014, 130. [CrossRef] [PubMed]

58. Zhang, F.; Wen, Y.; Guo, X. CRISPR/Cas9 for genome editing: Progress, implications and challenges. Hum. Mol. Genet. 2014, 23, R40-R46. [CrossRef] [PubMed]

59. Nozaki, Y.; Honda, Y.; Tsujimoto, S.; Watanabe, H.; Kunimatsu, T.; Funabashi, H. Availability of human induced pluripotent stem cell-derived cardiomyocytes in assessment of drug potential for QT prolongation. Toxicol. Appl. Pharmacol. 2014, 278, 72-77. [CrossRef] [PubMed]

60. Moak, J.P. Developmental cellular electrophysiologic effects of d-sotalol on canine cardiac Purkinje fibers. Pediatr. Res. 1991, 29, 104-109. [CrossRef] [PubMed]

61. Carmeliet, E. Electrophysiologic and voltage clamp analysis of the effects of sotalol on isolated cardiac muscle and Purkinje fibers. J. Pharmacol. Exp. Ther. 1985, 232, 817-825. [PubMed]

62. Izumi-Nakaseko, H.; Nakamura, Y.; Wada, T.; Ando, K.; Kanda, Y.; Sekino, Y.; Sugiyama, A. Characterization of human iPS cell-derived cardiomyocyte sheets as a model to detect drug-induced conduction disturbance. J. Toxicol. Sci. 2017, 42, 183-192. [CrossRef] [PubMed]

63. Melgari, D.; Zhang, Y.; El Harchi, A.; Dempsey, C.E.; Hancox, J.C. Molecular basis of hERG potassium channel blockade by the class Ic antiarrhythmic flecainide. J. Mol. Cell. Cardiol. 2015, 86, 42-53. [CrossRef] [PubMed]

64. Ramos, E.; O'Leary, M.E. State-dependent trapping of flecainide in the cardiac sodium channel. J. Physiol. 2004, 560, 37-49. [CrossRef] [PubMed]

(C) 2017 by the authors. Licensee MDPI, Basel, Switzerland. This article is an open access article distributed under the terms and conditions of the Creative Commons Attribution (CC BY) license (http://creativecommons.org/licenses/by/4.0/). 